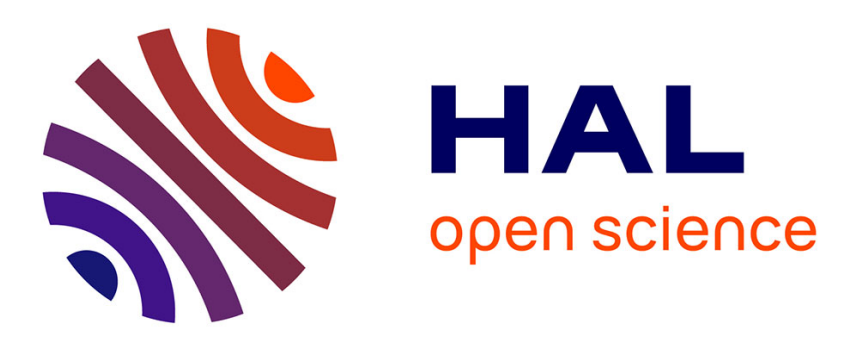

\title{
Validation of GOMOS-Envisat vertical profiles of O3, NO2, NO3, and aerosol extinction using balloon-borne instruments and analysis of the retrievals
}

Jean-Baptiste Renard, Gwenaël Berthet, Colette Brogniez, Valéry Catoire, Didier Fussen, Florence Goutail, Hermann Oelhaf, Jean-Pierre Pommereau, Howard K. Roscoe, Gerald Wetzel, et al.

\section{To cite this version:}

Jean-Baptiste Renard, Gwenaël Berthet, Colette Brogniez, Valéry Catoire, Didier Fussen, et al.. Validation of GOMOS-Envisat vertical profiles of O3, NO2, NO3, and aerosol extinction using balloonborne instruments and analysis of the retrievals. Journal of Geophysical Research Space Physics, 2008, 113, pp.A02302. 10.1029/2007JA012345 . hal-00243147

\section{HAL Id: hal-00243147 \\ https://hal.science/hal-00243147}

Submitted on 11 Jan 2016

HAL is a multi-disciplinary open access archive for the deposit and dissemination of scientific research documents, whether they are published or not. The documents may come from teaching and research institutions in France or abroad, or from public or private research centers.
L'archive ouverte pluridisciplinaire HAL, est destinée au dépôt et à la diffusion de documents scientifiques de niveau recherche, publiés ou non, émanant des établissements d'enseignement et de recherche français ou étrangers, des laboratoires publics ou privés. 


\title{
Validation of GOMOS-Envisat vertical profiles of $\mathrm{O}_{3}, \mathrm{NO}_{2}, \mathrm{NO}_{3}$, and aerosol extinction using balloon-borne instruments and analysis of the retrievals
}

\author{
Jean-Baptiste Renard, ${ }^{1}$ Gwenaël Berthet, ${ }^{1}$ Colette Brogniez, ${ }^{2}$ Valery Catoire, ${ }^{1}$ \\ Didier Fussen, ${ }^{3}$ Florence Goutail, ${ }^{4}$ Hermann Oelhaf, ${ }^{5}$ Jean-Pierre Pommereau, ${ }^{4}$ \\ Howard K. Roscoe, ${ }^{6}$ Gerald Wetzel, ${ }^{5}$ Michel Chartier, ${ }^{1}$ Claude Robert, ${ }^{1}$ Jean-Yves Balois, ${ }^{2}$ \\ Christian Verwaerde, ${ }^{2}$ Frédérique Auriol, ${ }^{2}$ Philippe François, ${ }^{2}$ Bertrand Gaubicher, ${ }^{1}$ \\ and Patrick Wursteisen ${ }^{7}$
}

Received 13 February 2007; revised 25 July 2007; accepted 24 October 2007; published 6 February 2008.

[1] The UV-visible Global Ozone Monitoring by Occultation of Stars (GOMOS) instrument onboard Envisat performs nighttime measurements of ozone, $\mathrm{NO}_{2}, \mathrm{NO}_{3}$ and of the aerosol extinction, using the stellar occultation method. We have conducted a validation exercise using various balloon-borne instruments in different geophysical conditions from 2002 to 2006, using GOMOS measurements performed with stars of different magnitudes. GOMOS and balloon-borne vertical columns in the middle stratosphere are in excellent agreement for ozone and $\mathrm{NO}_{2}$. Some discrepancies can appear between GOMOS and balloon-borne vertical profiles for the altitude and the amplitude of the concentration maximum. These discrepancies are randomly distributed, and no bias is detected. The accuracy of individual profiles in the middle stratosphere is $10 \%$ for ozone and $25 \%$ for $\mathrm{NO}_{2}$. On the other hand, the GOMOS NO 3 retrieval is difficult and no direct validation can be conducted. The GOMOS aerosol content is also well estimated, but the wavelength dependence can be better estimated if the aerosol retrieval is performed only in the visible domain. We can conclude that the GOMOS operational retrieval algorithm works well and that GOMOS has fully respected its primary objective for the study of the trends of species in the middle stratosphere, using the profiles in a statistical manner. Some individual profiles can be partly inaccurate, in particular in the lower stratosphere. Improvements could be obtained by reprocessing some GOMOS transmissions in case of specific studies in the middle and lower stratosphere when using the individual profiles.

Citation: Renard, J.-B., et al. (2008), Validation of GOMOS-Envisat vertical profiles of $\mathrm{O}_{3}, \mathrm{NO}_{2}, \mathrm{NO}_{3}$, and aerosol extinction using balloon-borne instruments and analysis of the retrievals, J. Geophys. Res., 113, A02302,

doi:10.1029/2007JA012345.

\section{Introduction}

[2] Global Ozone Monitoring by Occultation of Stars (GOMOS) onboard the European satellite Envisat is an instrument for the retrieval of stratospheric and mesospheric species that exhibit absorption lines in the UV-visible and near infrared domain [Bertaux et al., 2004; Kyrölä et al., 2004]. GOMOS performs measurements using the stellar

\footnotetext{
${ }^{1}$ LPCE-CNRS/Université d'Orléans, Orléans cedex 2, France.

${ }^{2}$ LOA/CNRS, Villeneuve d'Ascq cedex, France.

${ }^{3}$ IASB, Brussels, Belgium.

${ }^{4}$ Service d'Aéronomie, Verrières le Buisson cedex, France.

${ }^{5}$ Institut für Meteorologie und Klimaforschung, Forschungszentrum Karlsruhe GmbH, Karlsruhe, Germany.

${ }^{6}$ British Antarctic Survey/NERC, Cambridge, UK.

${ }^{7}$ European Space Agency, ESTEC-SMS, Noordwijk, Netherlands.
}

Copyright 2008 by the American Geophysical Union. 0148-0227/08/2007JA012345 occultation method during the setting of stars, allowing mainly the retrieval of the vertical profiles of ozone, $\mathrm{NO}_{2}$, $\mathrm{NO}_{3}$, the extinction coefficient of aerosols (at $500 \mathrm{~nm}$ ) and estimation of its wavelength dependence. GOMOS was mainly dedicated to evaluate accurately the ozone trend at all latitudes, in the stratosphere and the mesosphere. Nevertheless, the other measurements can help to better document stratospheric nitrogen chemistry at different latitudes, and to estimate the aerosol content in the lower and middle stratosphere.

[3] GOMOS allows nighttime measurements of $\mathrm{NO}_{3}$ that cannot be observed during daytime and of $\mathrm{NO}_{2}$ around its maximum concentration over its diurnal cycle. Also, OClO [Fussen et al., 2006] and water vapor can be tentatively retrieved from the GOMOS measurements. The use of different stars, typically brighter than magnitude 3, allows the instrument to obtain an almost global coverage which cannot be achieved when the Sun is used as a light source. 
In particular, GOMOS can provide unique measurements during the winter polar night.

[4] As done for many satellite instruments it is necessary to validate the GOMOS profiles in order to estimate the accuracy of individual profiles and to search for possible bias both in altitude registration and in the absolute values of the species concentrations. An intensive validation work has been conducted between ozone lidar, ozone sounding, microwave radiometer and GOMOS measurements, and no bias was found statistically [Meijer et al., 2004]. Marchand et al. [2004] have analyzed the self-consistency of GOMOS $\mathrm{NO}_{3}, \mathrm{NO}_{2}$ and $\mathrm{O}_{3}$ data using chemical data assimilation; they also came to the same conclusion, although the $\mathrm{NO}_{2}$ and $\mathrm{NO}_{3}$ comparisons show very scattered results.

[5] Another validation exercise is to conduct direct validation of the individual GOMOS profiles. Since GOMOS uses different stars with different magnitudes and colors, the signal-to-noise ratio can vary from one profile to another. Then it is necessary to conduct the direct validation of the GOMOS profiles when different stars are observed. This can be done at different latitudes and during different geophysical conditions using balloon-borne instruments that can perform measurements from the tropopause up to altitudes in the $30-40 \mathrm{~km}$ range. It is obvious that such an exercise is a set of "one-shot" validations mainly dedicated to evaluate the absolute accuracy of each individual profile. Nevertheless, an estimation of bias can be conducted if enough balloon profiles are available.

[6] This direct validation will concern vertical profiles of ozone, of $\mathrm{NO}_{2}$, of $\mathrm{NO}_{3}$ and of the aerosol extinction coefficient. It will not be conducted for water vapor and $\mathrm{OClO}$ since their retrievals are difficult and the individual profiles are not accurate enough. The validation will not be conducted for high resolution temperatures profiles because no balloon-borne temperature profiles are available at the exact place of the GOMOS measurements.

[7] Three different steps will be conducted. First, the GOMOS vertical profiles and balloon profiles will be compared. Secondly, a statistical analysis will be conducted in order to estimate the accuracy of the profiles. Thirdly, the GOMOS transmission spectra will be reanalyzed using an algorithm similar to those used for balloon instruments that perform remote sensing measurements in the UV-visible, in order to evaluate the "operational GOMOS" processor. A specific section will be dedicated to the aerosol retrievals.

\section{Ballon-Borne Instruments and Validation Campaigns}

[8] Six balloon-borne instruments have been used in dedicated campaigns for the GOMOS validation: Absorption par les Minoritaire Ozone et NOx (AMON), Micro Radiomètre Ballon (MicroRADIBAL), Michelson Interferometer for Passive Atmospheric Sounding (MIPAS-B2), Spectroscopie d'Absorption Lunaire pour l'Observation des Minoritaires Ozone et NOx (SALOMON), Spectroscopie d'Absorption pour l'Observation Zénitale (SAOZ), and Spectromètre Infra Rouge d'Absorption par Diodes Laser Embarquées (SPIRALE). AMON is a UV-visible spectrometer which, just like GOMOS, uses stars as light source [Renard et al., 1996]. Its ozone, $\mathrm{NO}_{2}$ and $\mathrm{NO}_{3}$ measurements will be used for validation. MicroRADIBAL is a radiometer measuring the sunlight scattered by the atmosphere in the near infra red, at $730 \mathrm{~nm}$ and $865 \mathrm{~nm}$ [Brogniez et al., 2003]. Its detected radiances are converted to aerosol extinction using Mie scattering calculations and will be used for comparison with GOMOS aerosol extinction. MIPAS-B2 is a limb viewing Fourier Transform InfraRed (FTIR) Spectrometer [Friedl-Vallon et al., 2004; Wetzel et al., 2006], like MIPAS onboard Envisat. Its ozone and $\mathrm{NO}_{2}$ measurements will be used for validation. SALOMON is a UV-visible spectrometer using the Moon as a light source [Renard et al., 2000]. Its ozone, $\mathrm{NO}_{2}, \mathrm{NO}_{3}$ and aerosol extinction measurements will be used for validation. $\mathrm{SAOZ}$ is a UV-visible spectrometer using the Sun as light source [Pommereau and Piquard, 1994]. Its ozone measurements will be used for validation. SPIRALE is a tunable diode laser absorption spectrometer [Moreau et al., 2005], allowing in situ measurements of species. Its ozone and $\mathrm{NO}_{2}$ measurements will be used for validation. Ozone soundings have been performed during one SALOMON flight at mid latitudes and during one SPIRALE flight at high latitudes, in order to check the consistency between the different types of measurements.

[9] All the balloon instruments except SPIRALE performed remote sensing measurements, as do satellite instruments. The validation exercise conducted here will mainly concern vertical profiles obtained after performing a spatial inversion. These profiles could differ from "real" vertical distribution of the species that could be obtained by in situ measurements, in particular if local enhancements are present. This is discussed in detail in the paper of Berthet et al. [2007].

[10] The collocation criterion we adopted between GOMOS and balloon measurements (considered at the middle of the flight trajectory) are roughly less than 500 $\mathrm{km}$ in the same geophysical conditions (this is essential at high latitude when the vortex is present) and less than $3 \mathrm{~h}$, except for ozone and aerosol extinction where the time criteria can be extended to $6 \mathrm{~h}$. In fact, it is difficult to provide a meaningful accurate estimation of the time and distance collocations between GOMOS and balloon measurements. This problem is due to the relative motion of the satellite and of the balloon, to the fact that balloon measurements take tens of minutes instead of less than 1 minute for GOMOS, and to the retrievals (expect for SPIRALE) that assume horizontal homogeneous layers from tens to few hundred kilometers.

[11] Five validation campaigns were conducted at different latitudes and during different geophysical conditions between 2002 and 2006 involving GOMOS observations using bright and weak stars. At mid latitudes balloons were launched from Aire sur l'Adour, France (latitude $42^{\circ} 43^{\prime} \mathrm{N}$, longitude $\left.0^{\circ} 15^{\prime} \mathrm{W}\right)$, and at high latitude from Kiruna, Northern Sweden (latitude $67^{\circ} 53^{\prime} \mathrm{N}$, longitude $21^{\circ} 05^{\prime} \mathrm{E}$ ); details are given in Table 1. Validation was conducted in March 2003 during a Polar Stratospheric Cloud event (PSC) [Alfred et al., 2006] located at altitudes between 21 and $26 \mathrm{~km}$, and in March 2004 just outside the polar vortex.

[12] In the following, comparison between operational GOMOS V5.0 data and balloon-borne measurements will be performed in the altitude range where both profiles are available. Some GOMOS data are sometimes available at altitudes lower than balloon measurements (with large 
Table 1. Conditions of Measurements. ASA is for Aire sur l'Adour, France; KRN is for Kiruna, Northern Sweden

\begin{tabular}{|c|c|c|c|c|c|}
\hline Date & Place & $\begin{array}{l}\text { Balloon-borne } \\
\text { Instrument }\end{array}$ & Measured Species & $\begin{array}{c}\text { Time of } \\
\text { GOMOS Measurements }\end{array}$ & $\begin{array}{c}\text { Magnitude } \\
\text { of the stars } \\
\text { observed by GOMOS }\end{array}$ \\
\hline 19 Sept. 2002 & ASA & SALOMON & $\mathrm{O}_{3}, \mathrm{NO}_{2}, \mathrm{NO}_{3}$ & $21: 24$ & 1.7 \\
\hline 24 Sept. 2002 & ASA & MIPAS & $\mathrm{O}_{3}, \mathrm{NO}_{2}$ & $22: 07$ & 2.4 \\
\hline 21 Jan. 2003 & KRN & SPIRALE & $\mathrm{O}_{3}, \mathrm{NO}_{2}$ & 19:54 & 2.0 \\
\hline 1 March 2003 & KRN & AMON & $\mathrm{O}_{3}, \mathrm{NO}_{2}, \mathrm{NO}_{3}$ & $22: 48$ & 2.6 \\
\hline 30 March 2003 & KRN & $\mathrm{SAOZ}$ & $\mathrm{O}_{3}$ & $20: 55$ and $20: 57$ & 2.7 and 2.6 \\
\hline 4 March 2004 & KRN & SALOMON & $\mathrm{O}_{3}, \mathrm{NO}_{2}, \mathrm{NO}_{3}$ & $22: 51$ & 2.6 \\
\hline 8 March 2004 & KRN & MicroRADIBAL & Aerosol extinction & $22: 23$ & 2.7 \\
\hline 8 June 2004 & ASA & SALOMON & $\mathrm{O}_{3}, \mathrm{NO}_{2}, \mathrm{NO}_{3}$ & $22: 27$ & 1.9 \\
\hline 16 Jan. 2006 & KRN & SALOMON & $\begin{array}{l}\mathrm{O}_{3}, \mathrm{NO}_{2}, \\
\quad \text { aerosol extinction }\end{array}$ & $20: 06$ & -1.4 \\
\hline 20 Jan. 2006 & KRN & SPIRALE & $\mathrm{O}_{3}, \mathrm{NO}_{2}$ & $19: 40$ & -1.4 \\
\hline
\end{tabular}

errors bars) but will not be taken into account. The GOMOS vertical sampling is about $1.5 \mathrm{~km}$; the real vertical resolutions, given in the Product Handbook of the GOMOS data, are larger. They are $2 \mathrm{~km}$ below $30 \mathrm{~km}$ and $3 \mathrm{~km}$ above for ozone, and $4 \mathrm{~km}$ for $\mathrm{NO}_{2}, \mathrm{NO}_{3}$ and aerosols. The GOMOS sampling is close to the $1-\mathrm{km}$ vertical sampling used commonly for balloon-borne instrument retrievals (except for the in situ SPIRALE measurements that have a vertical resolution less than $50 \mathrm{~m}$ ). The real vertical resolutions of the balloon profiles can differ from one instrument to another, but it is commonly assumed that balloon instruments have a vertical resolution similar or better than satellites instruments. We can postulate, at least as a first approximation, that all measurements have similar vertical resolution, allowing direct comparisons without smoothing procedures (except for SPIRALE). In any case, differences in resolution can affect the estimation of the absolute values of concentrations mainly where a profile exhibits strong vertical gradients but do not act significantly on the estimation of the total content of the species in the stratosphere.

[13] It must be noticed that although the measurements are performed in same geophysical conditions, small-scale variations of the species concentrations could occur between the locations of GOMOS and of the balloon measurements. The path length of GOMOS lines of sight in the atmosphere is longer than those of balloon-borne instruments, minimizing their relative contribution to the total estimation of the slant column densities. These variations will have less influence on the GOMOS retrievals than on the balloon retrievals [Berthet et al., 2007]. Then, some (small) differences could appear during the comparison of the individual profiles, but they could disappear when performing a statistical analysis using all the profiles.

\section{Comparison Results for Ozone}

[14] Figures 1-3 present the comparison between ozone GOMOS and balloon measurements at midlatitudes, and

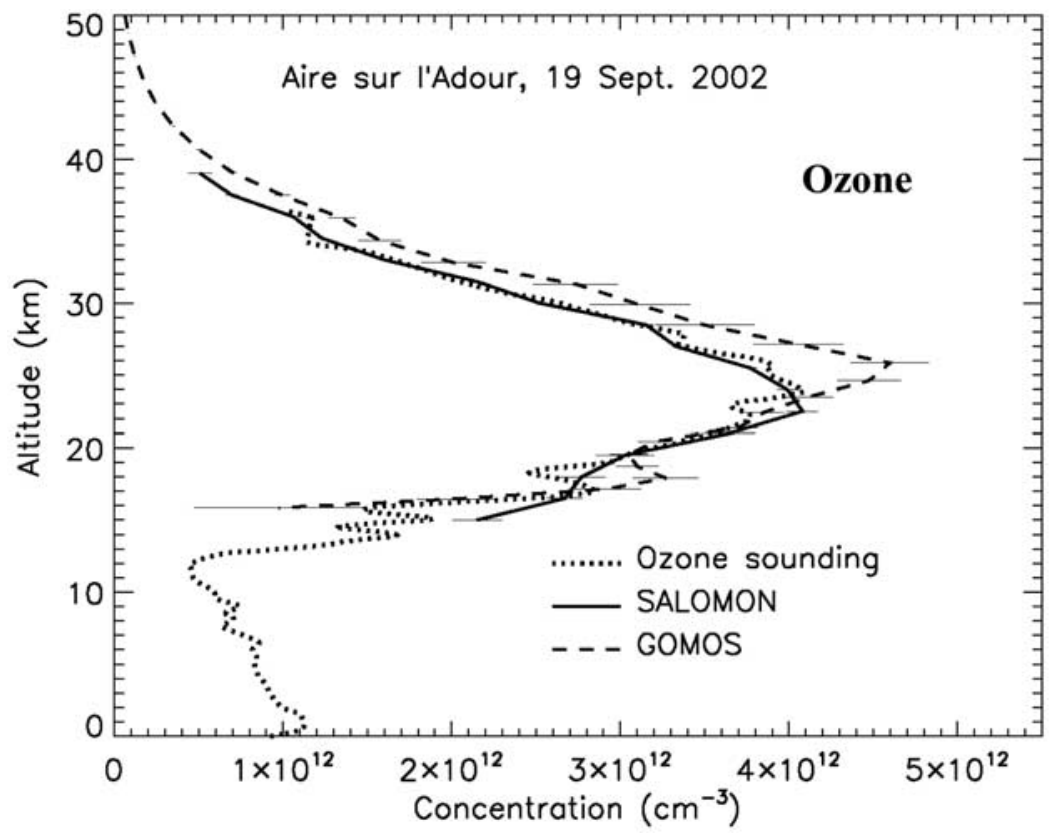

Figure 1. Comparison between ozone measurements by GOMOS, SALOMON and ozone sounding, at midlatitudes. 


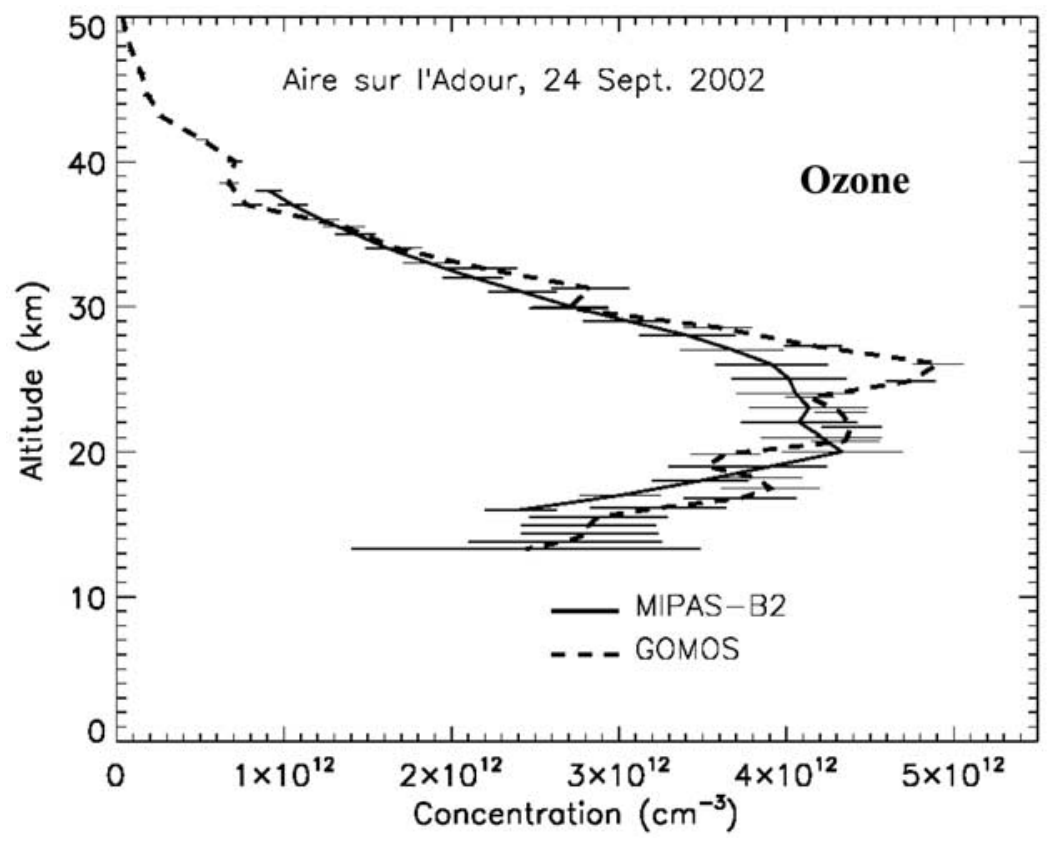

Figure 2. Comparison between ozone measurements by GOMOS and MIPAS-B2, at midlatitudes (MIPAS-B2 error bars comprise random and systematic error components).

Figures 4-9 present the comparison at high latitudes. Ozone soundings on Figure 1 and on Figure 9 are in excellent agreement with balloon measurements, confirming the accuracy of the instruments used for the validation. In Figure 1, the GOMOS profile exhibits a significant overestimation when compared to SALOMON; also, the altitude of the concentration maximum detected by GOMOS is higher. In Figure 6, the GOMOS profile is underestimated when compared to SAOZ, and the altitude of maximum concentration is higher. In Figure 5, the agreement between the AMON profiles using two different stars and the GOMOS profile is poor. The presence of PSCs in the $21-26 \mathrm{~km}$ altitude range can induce strong low frequency spectral fluctuations [Rivière et al., 2000] that affect the species retrieval. Indeed, some unrealistic undulations are present in the vertical profiles, confirming that the retrieval using remote sensing measurement is difficult when PSCs are present. Finally, some GOMOS profiles are also in very good agreement with balloon measurements, as presented in Figure 8 . Then, no systematic discrepancies can be pointed out.

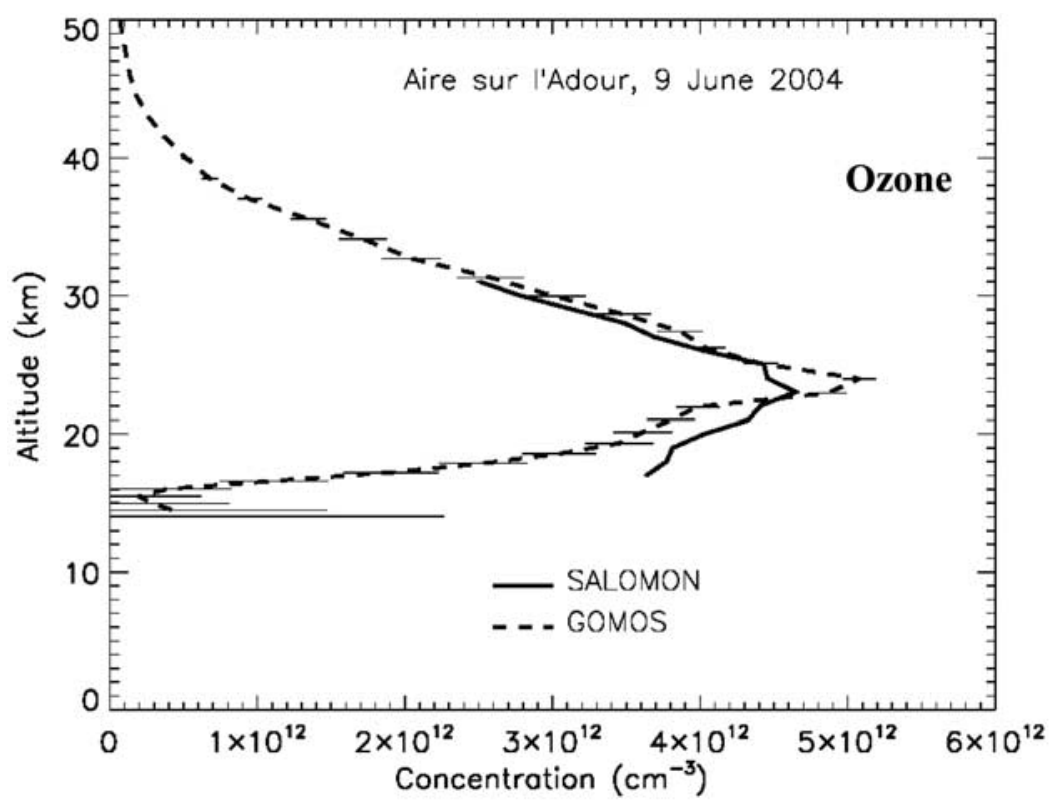

Figure 3. Comparison between ozone measurements by GOMOS and SALOMON, at midlatitudes. 


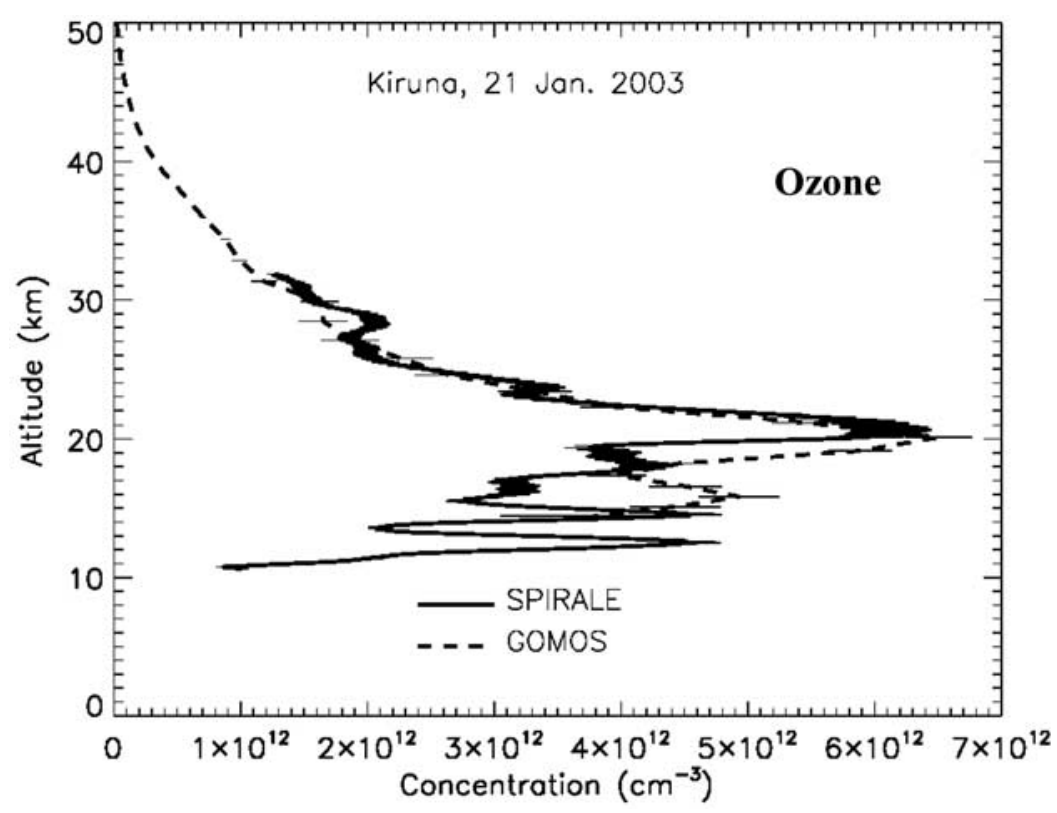

Figure 4. Comparison between ozone measurements by GOMOS and SPIRALE, at high latitudes.

[15] Excluding the measurements during the PSC event, the 8 case studies presented above can be used in order to evaluate the accuracy of GOMOS. The difference between the altitudes of maximum concentration of GOMOS and balloon-borne measurements is calculated for each casestudy. The 8 values are then averaged, giving a mean difference of $1.5 \pm 2.5 \mathrm{~km}$. Since the GOMOS vertical resolution is $2 \mathrm{~km}$ in this part of the stratosphere, this difference for altitude estimation is not significant. This result is in agreement with the conclusion obtained by Meijer et al. [2004]. The same method is applied for the difference between concentration maxima. Above $15 \mathrm{~km}$, the mean difference is $9.2 \times 10^{10} \pm 6.1 \times 10^{11}$ molecule $\mathrm{cm}^{-3}$ corresponding to a bias of about $1.5 \%$ (assuming a mean concentration maximum of $6 \times 10^{12}$ molecule $\mathrm{cm}^{-3}$ ) and uncertainty of $10 \%$ for the individual profiles (the error is calculated at $1-\sigma$ RMS).

[16] Figure 10 presents the relative errors calculated by dividing the difference between GOMOS and balloon profiles by the balloon profile, for each case study. The differences are then averaged when at least 4 profiles are available in a vertical range of $2 \mathrm{~km}$. The standard error of the mean is calculated from the standard error divided by the square root of the number of profiles used for the

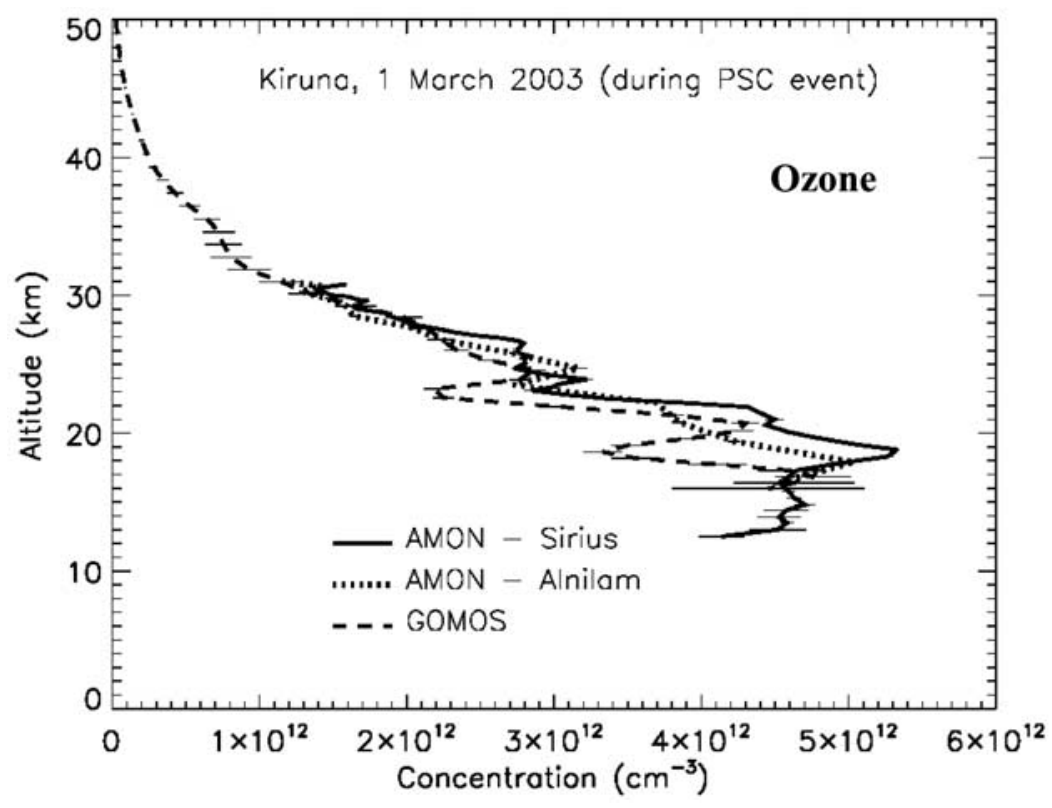

Figure 5. Comparison between ozone measurements by GOMOS and AMON, at high latitudes (two profiles using the stars Sirius and Alnilam were available for AMON measurements). PSCs were present at altitudes between 21 and $26 \mathrm{~km}$. 


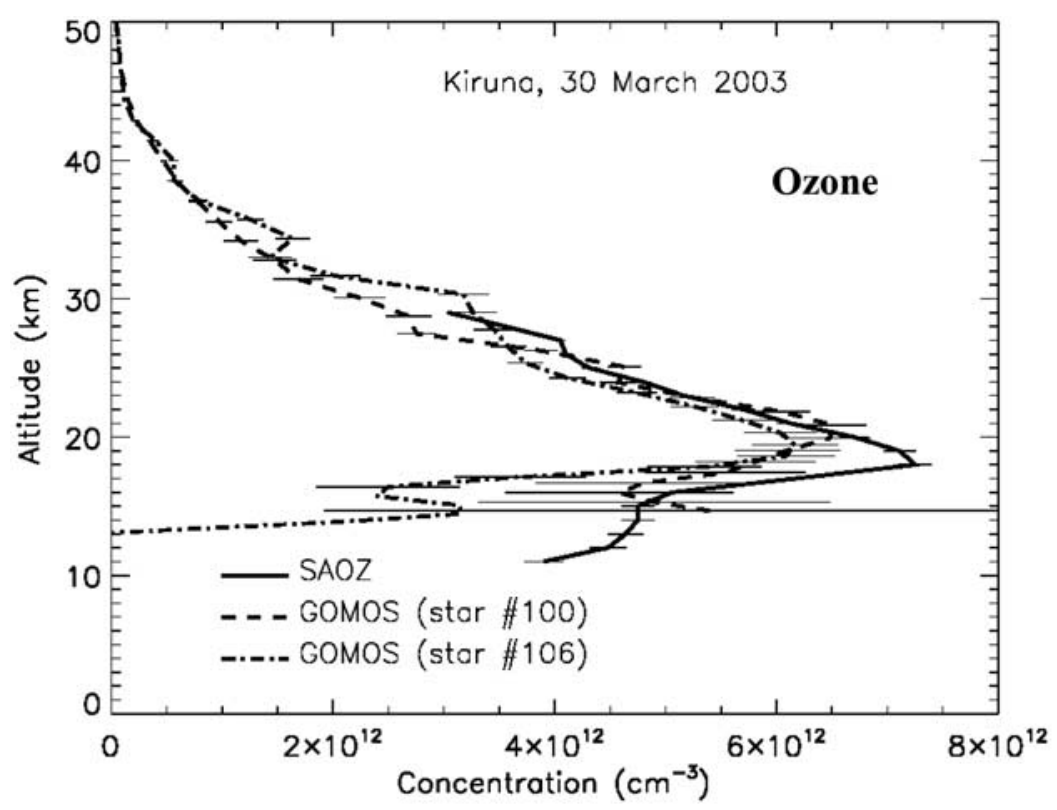

Figure 6. Comparison between ozone measurements by GOMOS and SAOZ, at high latitudes (two GOMOS profiles are collocated with SAOZ measurements). Star number 100 has magnitude of 2.6, and star number 106 has magnitude of 2.7 .

calculation. Even with a low number of profiles, no significant bias is present in the GOMOS profiles in the middle stratosphere between 17 and $30 \mathrm{~km}$, with an average value of $-0.3 \%$. The $1-\sigma$ error is $10 \%$ between 20 and $30 \mathrm{~km}$, confirming the result previously obtained with the concentration maxima. The vertical profiles can be converted into vertical columns in order to estimate the total amount of ozone in the stratosphere above $15 \mathrm{~km}$. The average difference between GOMOS and balloon-borne vertical columns is close to zero $\left(-1.9 \times 10^{15}\right.$ molecule $\mathrm{cm}^{-2}$, for an average total column of $6.9 \times 10^{18}$ molecule $\mathrm{cm}^{-2}$ ) in agreement with the results presented in Figure 10 for concentrations; the $1-\sigma$ error is about than $1 \%$. These results prove the ability to use GOMOS for global trend studies of ozone in the middle stratosphere, excluding the measurements obtained during PSCs events.

[17] The GOMOS individual profiles are inaccurate in the lower stratosphere below $17 \mathrm{~km}$ down to the tropopause, when compared to balloon profiles. This problem prevents from using individual profiles for case studies in this part of

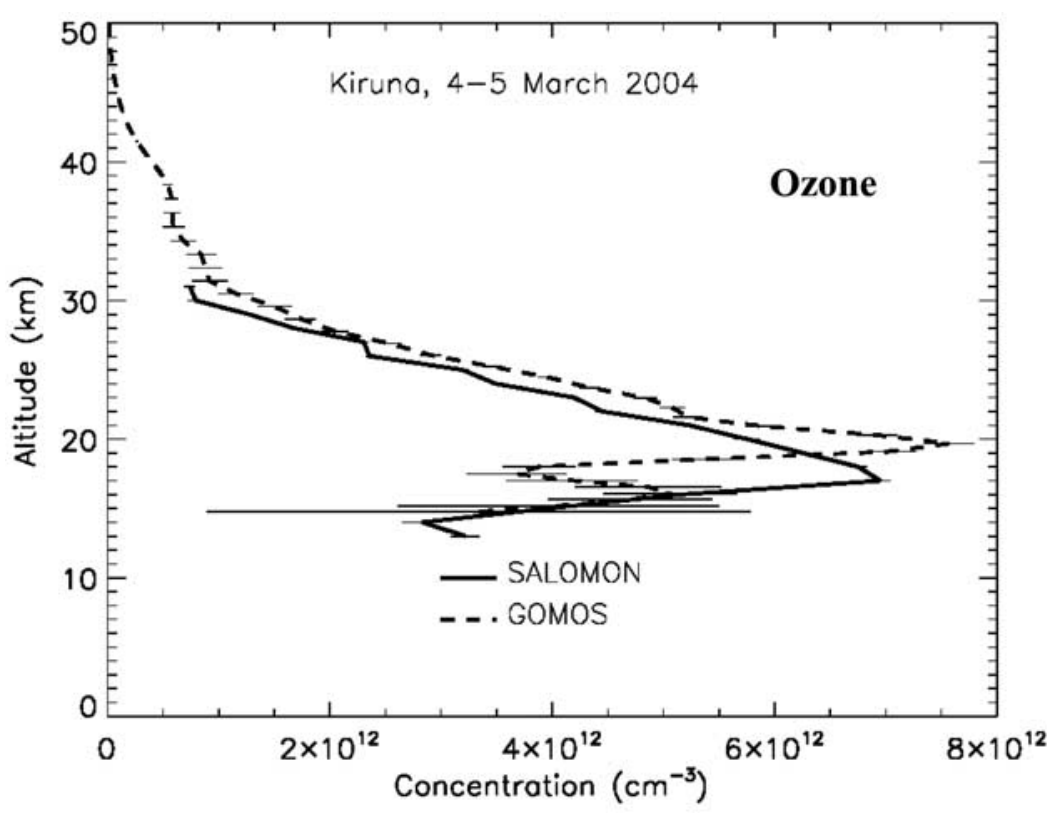

Figure 7. Comparison between ozone measurements by GOMOS and SALOMON, at high latitudes. 


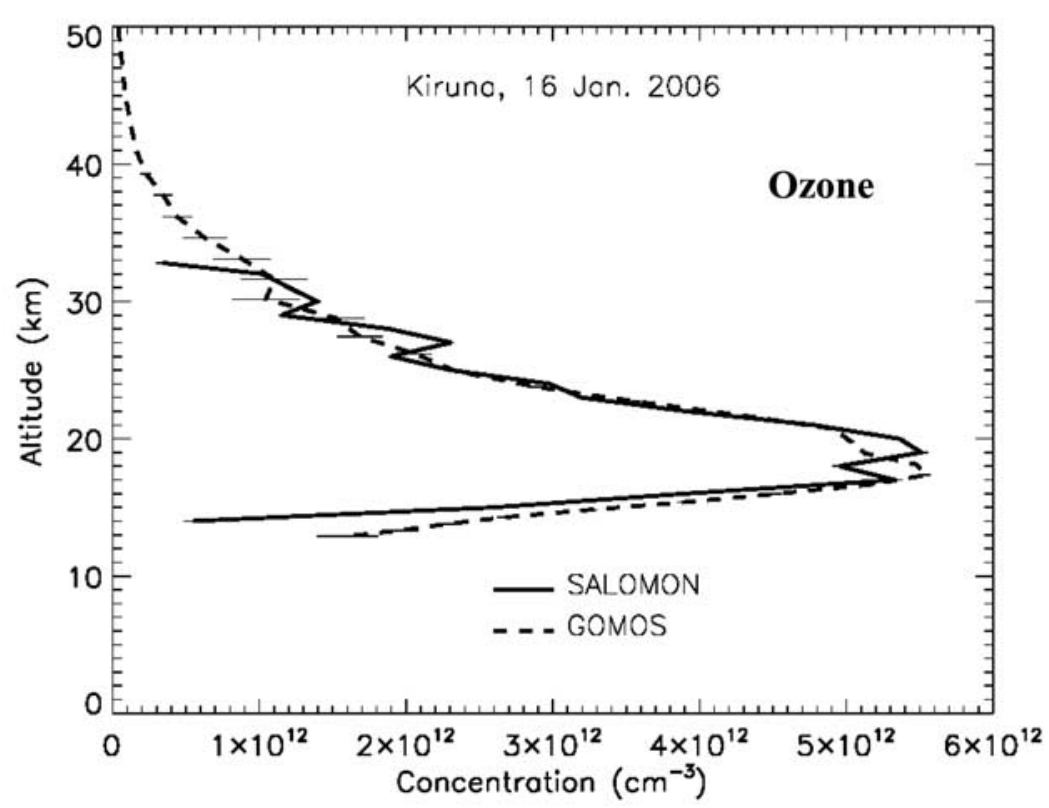

Figure 8. Comparison between ozone measurements by GOMOS and SALOMON, at high latitudes.

the atmosphere, in particular when measurements are conducted using a weak magnitude star as shown in Figure 6.

\section{Comparison Results for $\mathrm{NO}_{2}$}

[18] Figures 11-13 present the comparison between $\mathrm{NO}_{2}$ GOMOS and balloon measurements at midlatitudes, and Figures 14-18 present the comparison at high latitudes. In the middle stratosphere the profiles are qualitatively in agreement. Some strong discrepancies occur in the lower stratosphere (below $20 \mathrm{~km}$ ), in particular during the PSC event (Figure 15), or sometimes when secondary concentration peaks are present. These additional peaks could be due to dynamics when air masses originating from different latitudes remain vertically unmixed, and/or when charged particles originating from a solar eruption produce strong local enhancement in NOx content [Seppälä et al., 2004; Randall et al., 2005; Renard et al., 2006]. The presence of such (local) enhancements disrupts the assumption of spherical symmetry used in the retrieval, especially if their size is smaller than the path length of the line of sight (of the order of few hundreds kilometers in the lower stratosphere). This can produce inaccurate profiles containing artificial vertical enhancements [Berthet et al., 2007] at altitudes depending on the geometry of the measurements.

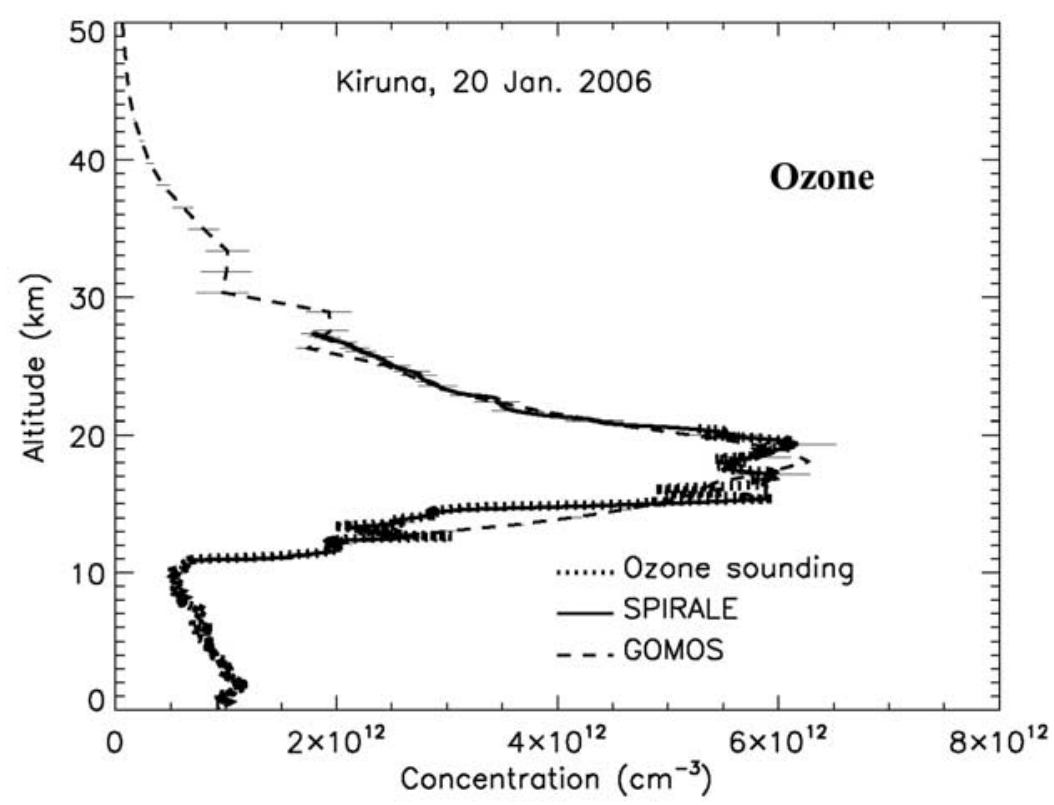

Figure 9. Comparison between ozone measurements by GOMOS, SPIRALE and ozone sounding, at high latitudes (only few SPIRALE errors bars are plotted for clarity). 


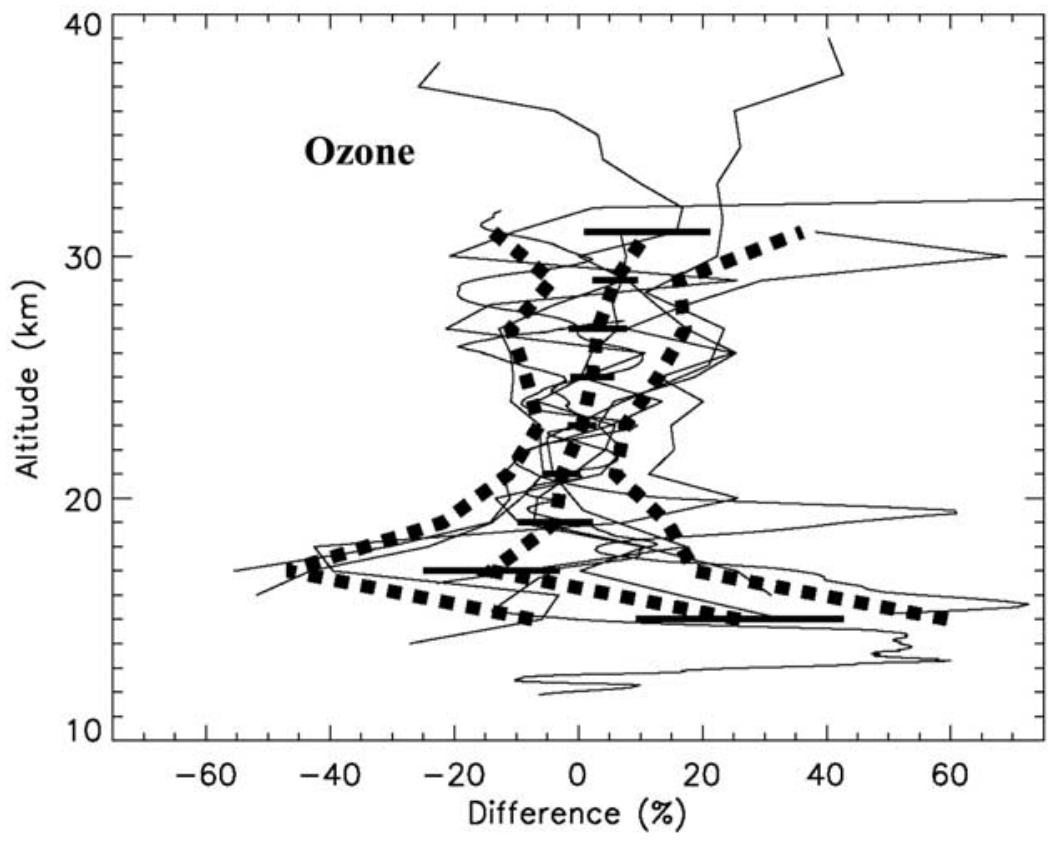

Figure 10. Relative differences between balloon and GOMOS profiles (full lines) for ozone. The central dashed line represents the mean difference taking into account all the flights (averaged over 2-km in vertical) with the standard error of the mean; the external dashed lines represent the $\pm 1-\sigma$ RMS error.

[19] Excluding the measurements during the PSC event, the 7 profiles studied here are averaged in order to evaluate the accuracy of GOMOS. The difference for the altitude of maximum concentration is $0.7 \pm 1.3 \mathrm{~km}$, which is smaller than the GOMOS vertical resolution of $4 \mathrm{~km}$. In the middle stratosphere above $20 \mathrm{~km}$, the mean of the differences of the maximum concentration is $2.0 \times 10^{7} \pm 3.3 \times 10^{8}$ molecule $\mathrm{cm}^{-3}$, corresponding to a bias of about $1 \%$ (assuming a mean concentration maximum of $2 \times 10^{9}$ molecule $\mathrm{cm}^{-3}$ ) and uncertainty of $17 \%$ (calculated at $1-\sigma \mathrm{rms}$ ).

[20] Figure 19 presents the relative errors calculated by dividing the difference between GOMOS and balloon profiles by the balloon profile, for each case study. As done previously for ozone, the differences are averaged when at least 4 profiles are available in a vertical range of $2 \mathrm{~km}$. The $1-\sigma$ error is about $25 \%$ in the $25-33 \mathrm{~km}$ altitude range, and

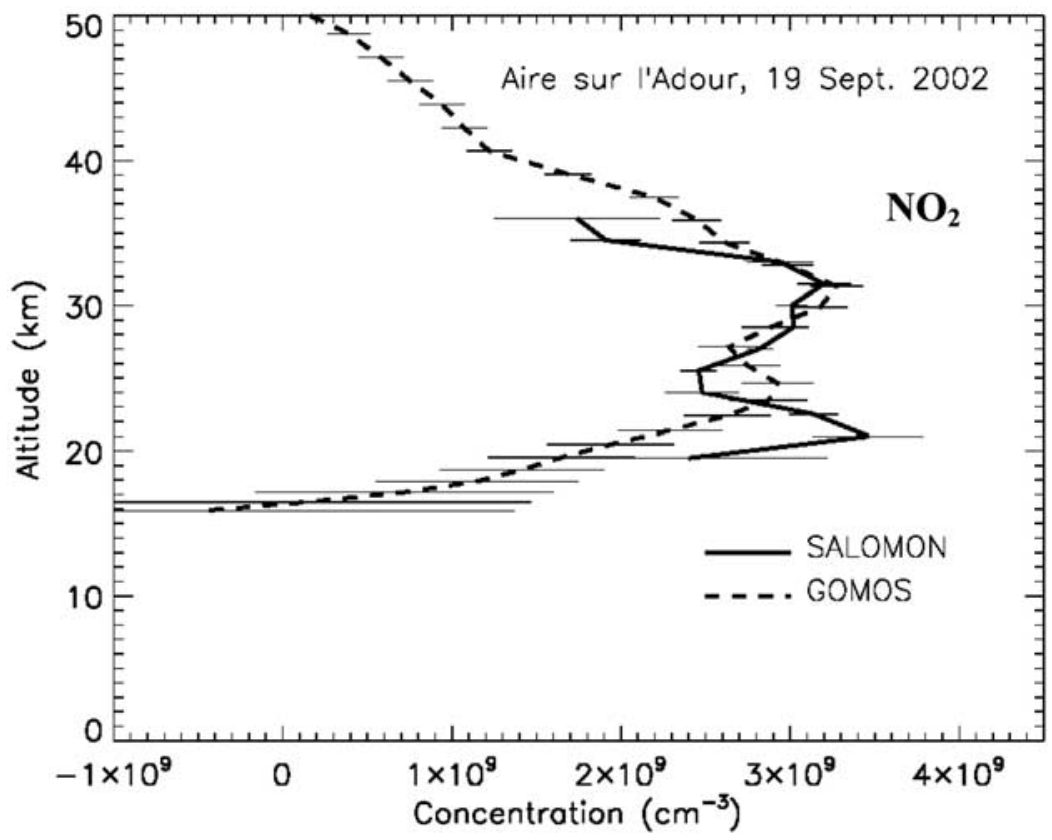

Figure 11. Comparison between $\mathrm{NO}_{2}$ measurements by GOMOS and SALOMON, at midlatitudes. 


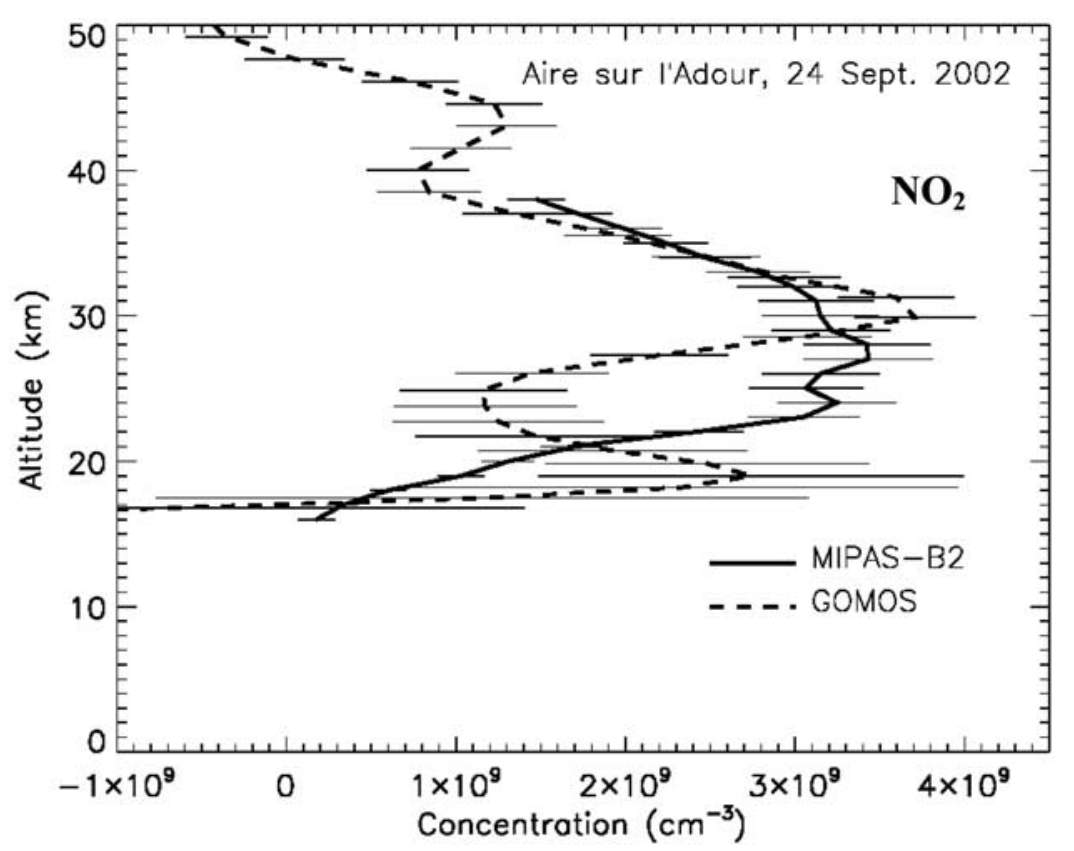

Figure 12. Comparison between $\mathrm{NO}_{2}$ measurements by GOMOS and MIPAS-B2, at midlatitudes.

increases strongly below $25 \mathrm{~km}$. This value is significantly higher than the one calculated for the concentration maxima. In fact, this difference percentage calculation is dominated by the results of high latitudes, with small amounts of $\mathrm{NO}_{2}$ in the middle and lower stratosphere, like those measured below $24 \mathrm{~km}$ by SPIRALE on 20 January 2006 (Figure 18). The calculation of the standard error of the mean shows no bias.
[21] The vertical profiles are converted into vertical columns in order to estimate the total amount of $\mathrm{NO}_{2}$ above $20 \mathrm{~km}$. The average difference between GOMOS and balloon-borne vertical columns is close to zero $(-4.4 \times$ $10^{12}$ molecule $\mathrm{cm}^{-2}$, for an average total column of $2.3 \times$ $10^{15}$ molecule $\mathrm{cm}^{-2}$ ), with a $1-\sigma$ RMS error of $2 \%$. These results show that there is no bias for the retrieval of the global amount of $\mathrm{NO}_{2}$ in the middle stratosphere. In the lower stratosphere, the GOMOS $\mathrm{NO}_{2}$ retrievals are inaccu-

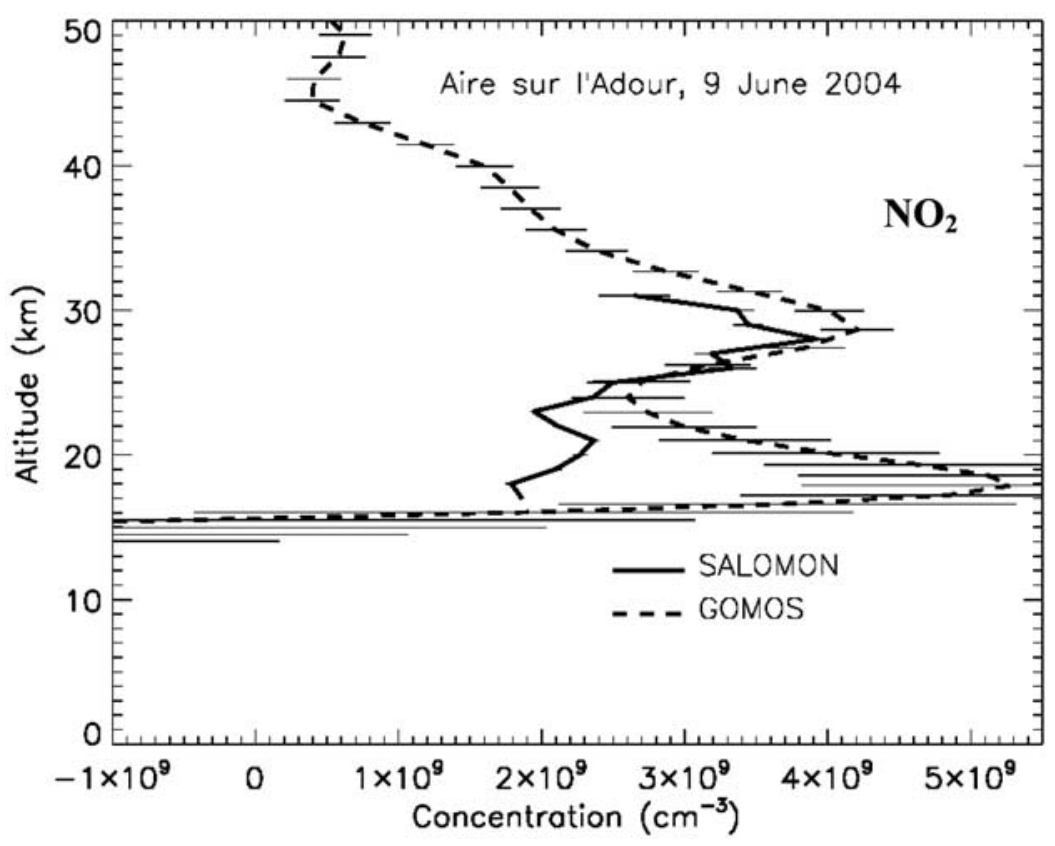

Figure 13. Comparison between $\mathrm{NO}_{2}$ measurements by GOMOS and SALOMON, at midlatitudes. 


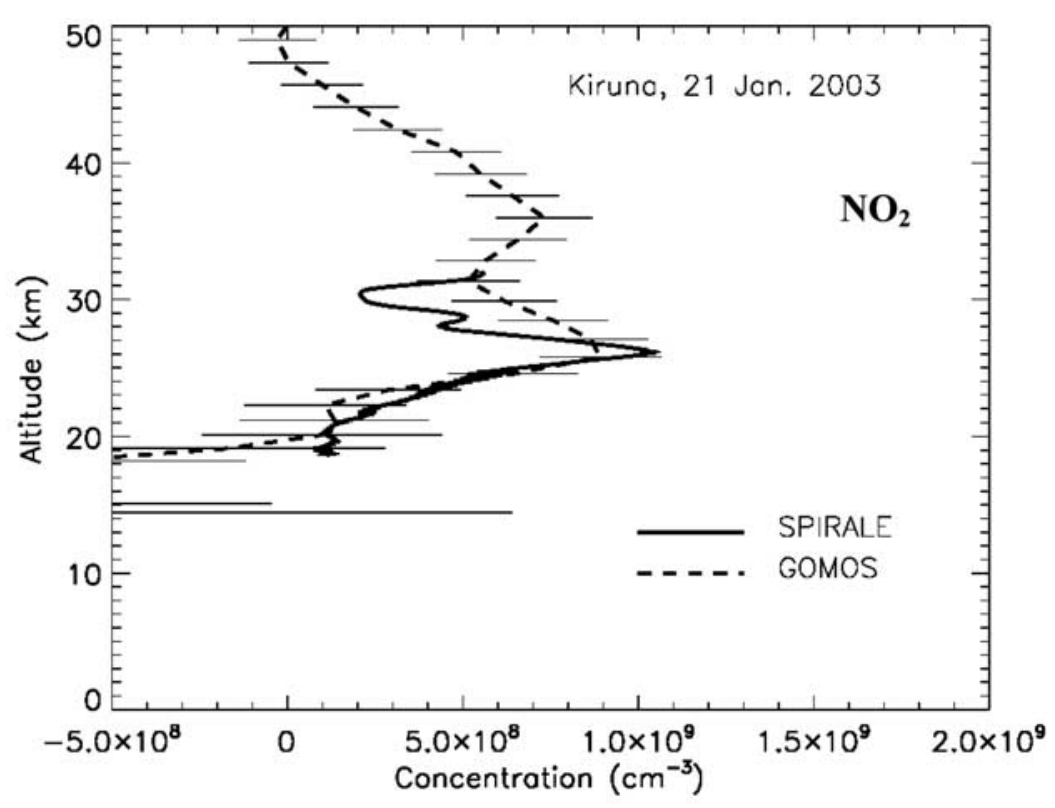

Figure 14. Comparison between $\mathrm{NO}_{2}$ measurements by GOMOS and SPIRALE, at high latitudes.

rate, probably due to of low signal-to-noise ratios, and the individual profiles cannot be used for case studies.

\section{Comparison Results for $\mathrm{NO}_{3}$}

[22] Figures 20-21 present the comparison of $\mathrm{NO}_{3}$ between GOMOS and the few balloon-borne measurements at midlatitudes, and Figures $22-23$ present the comparison at high latitudes. The retrieval of $\mathrm{NO}_{3}$ is difficult since only two large absorptions lines are present in the visible domain, of which the first one is contaminated by an $\mathrm{O}_{2}$ absorption line [Renard et al., 2005a]. The retrieval from the other line is difficult as it comes close to the detection limit of GOMOS detector resulting from the short exposure time
$(0.5 \mathrm{~s})$ and the weakness of the absorption. At midlatitudes, one profile is in agreement with balloon measurements (Figure 21) and the other one is in disagreement with balloon measurements (Figures 20 and 22). Nevertheless, the deduced GOMOS and balloon-borne vertical columns are in reasonable agreement for both profiles. At high latitudes, very small amounts of $\mathrm{NO}_{3}$ are expected during the polar night and under these circumstances measurements are difficult. When balloon data can be retrieved, then the comparison with GOMOS shows that the GOMOS error bars are realistic even if the profiles are very noisy.

[23] The same statistical analysis conducted for ozone and $\mathrm{NO}_{2}$ cannot be done is this comparison. Following the conclusion of Marchand et al. [2004] the GOMOS data can

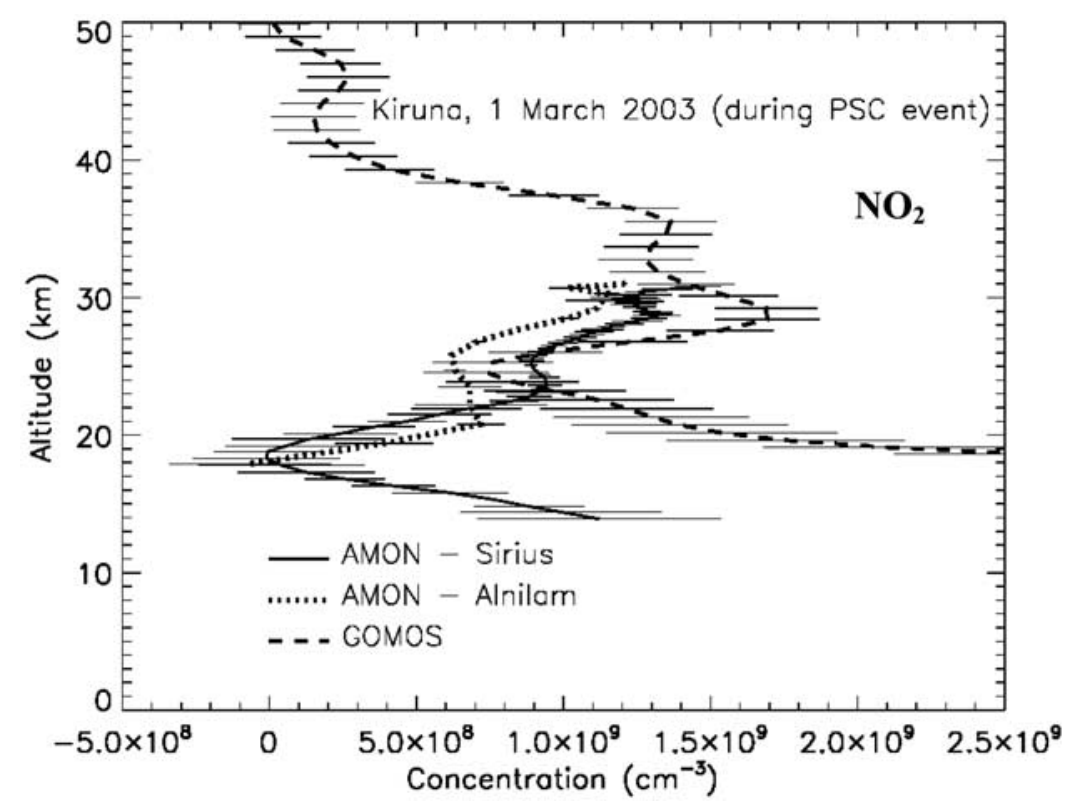

Figure 15. Comparison between $\mathrm{NO}_{2}$ measurements by GOMOS and AMON, at high latitudes. 


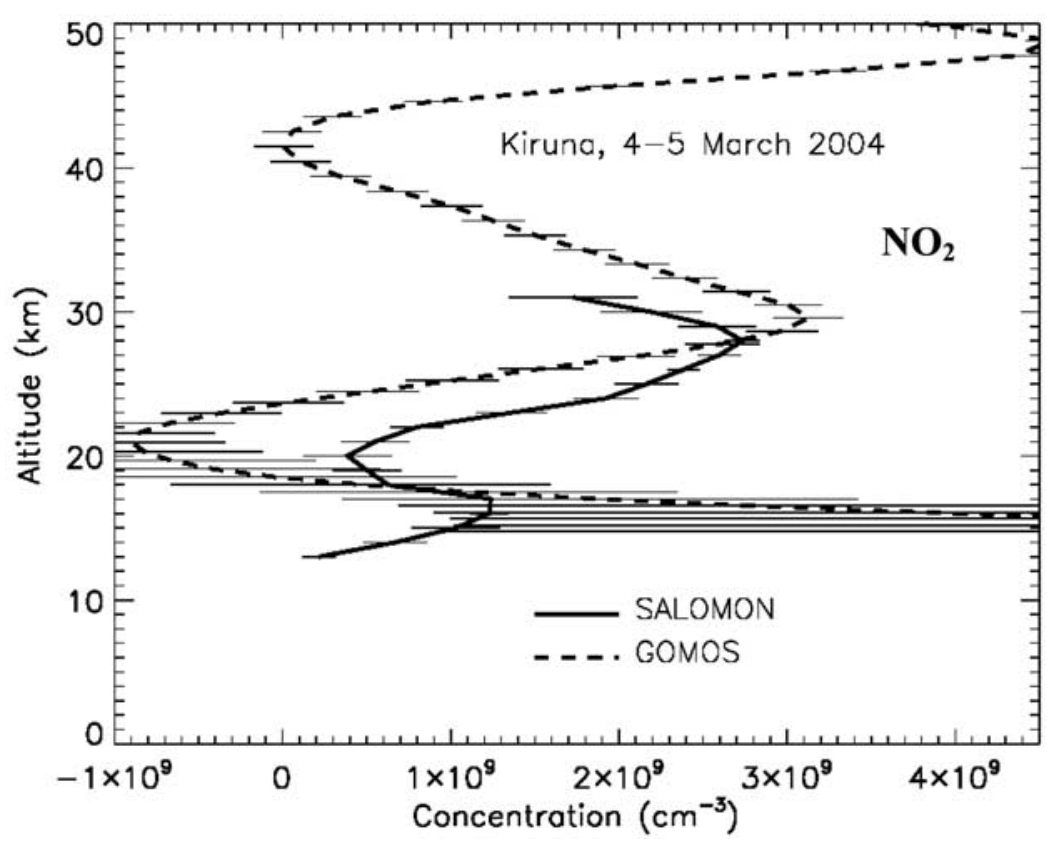

Figure 16. Comparison between $\mathrm{NO}_{2}$ measurements by GOMOS and SALOMON, at high latitudes.

be used for a statistical detection of $\mathrm{NO}_{3}$ in order to establish a global climatology [Hauchecorne et al., 2005], but the profiles cannot be used individually.

\section{Retrievals of GOMOS Profiles Using the "LPCE Processor"}

[24] We have shown above that the vertical columns (i.e., total amount) of ozone and $\mathrm{NO}_{2}$ for GOMOS and balloon measurements are in excellent agreement, although the various instruments have their own dedicated algorithms for the retrievals. The ozone and $\mathrm{NO}_{2}$ GOMOS data are highly accurate for climatology studies and for retrieving trends in the middle stratosphere, but the individual profiles have sometimes a poor accuracy that prevents them from being used for specific studies like troposphere-stratosphere exchange, ozone filamentation, or local chemical processes in the polar vortex. This problem could be due to the use of various stars, leading to fluxes varying from one occultation to another.

[25] It could be interesting to know if similar results or improvements can be obtained in the GOMOS retrievals,

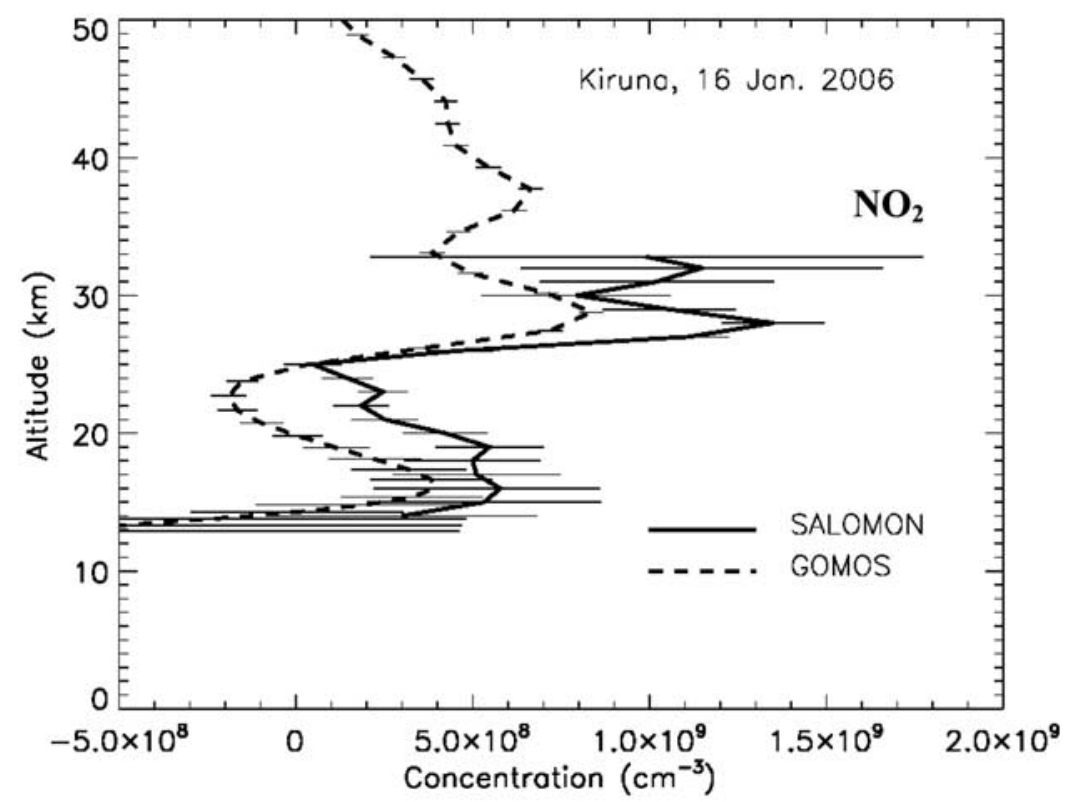

Figure 17. Comparison between $\mathrm{NO}_{2}$ measurements by GOMOS and SALOMON, at high latitudes. 


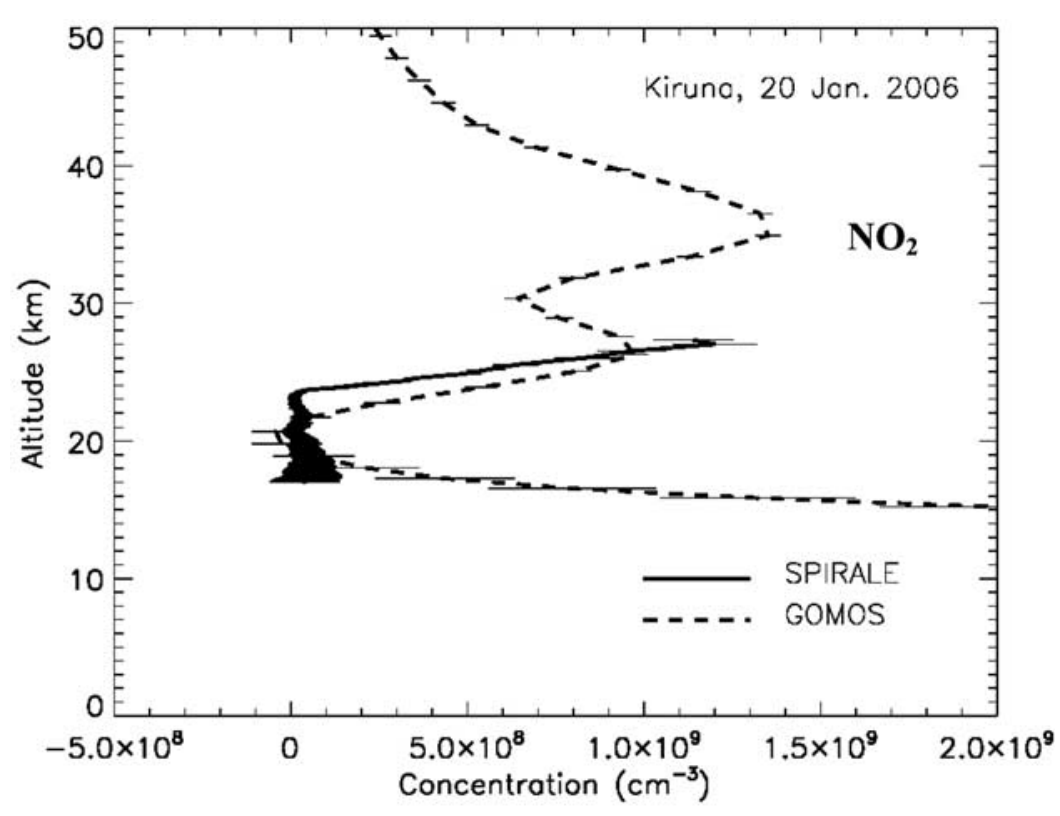

Figure 18. Comparison between $\mathrm{NO}_{2}$ measurements by GOMOS and SPIRALE, at high latitudes.

using another algorithm, hereafter called the "LPCE processor", derived from those commonly used for balloon instruments that perform remote sensing measurements in the UV-visible [e.g., Renard et al., 2000; Berthet et al., 2002]. Such reanalysis of the GOMOS transmissions allow the comparison between GOMOS and balloon profiles retrieved with the same method, and then the evaluation of the spectral and spatial inversion methods included in the "operational GOMOS" processor.

[26] The V5.0 GOMOS species retrievals are performed using a "global inversion". This means that all the species are retrieved simultaneously using the atmospheric transmissions in the whole spectral range from UV to near infra red. This method allows us the use of the UV domain for the retrieval of ozone in the mesosphere and in the high stratosphere, for which the ozone absorptions are too low in the visible domain. Nevertheless, two main problems could occur with this method. First, it does not high-pass filter the transmission spectrum, so the absolute calibration of the spectra relative to that obtained outside the atmosphere at the beginning of the occultation must be maintained. Hence local wavelength dependence of extinctions

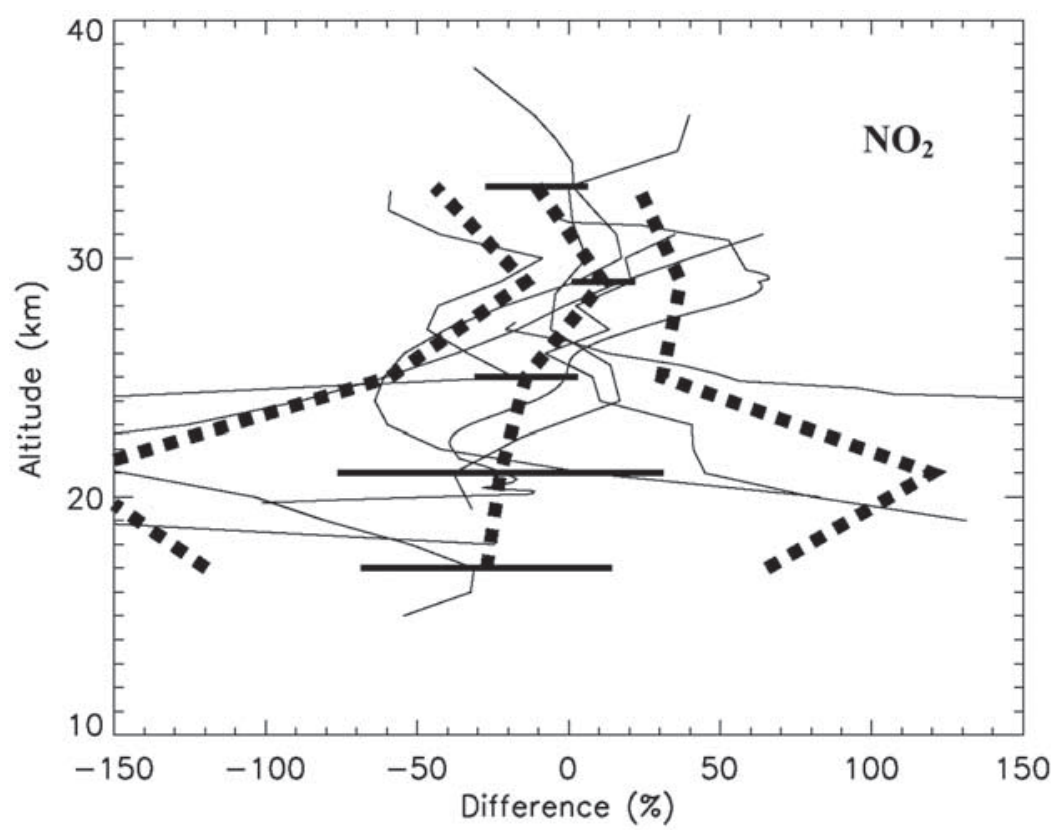

Figure 19. Relative differences between balloon and GOMOS profiles (full lines) for $\mathrm{NO}_{2}$. The central dashed line represents the mean difference taking into account all the flights (averaged over 2-km in vertical) with the standard error of the mean; the external dashed lines represent the $\pm 1-\sigma$ RMS error. 


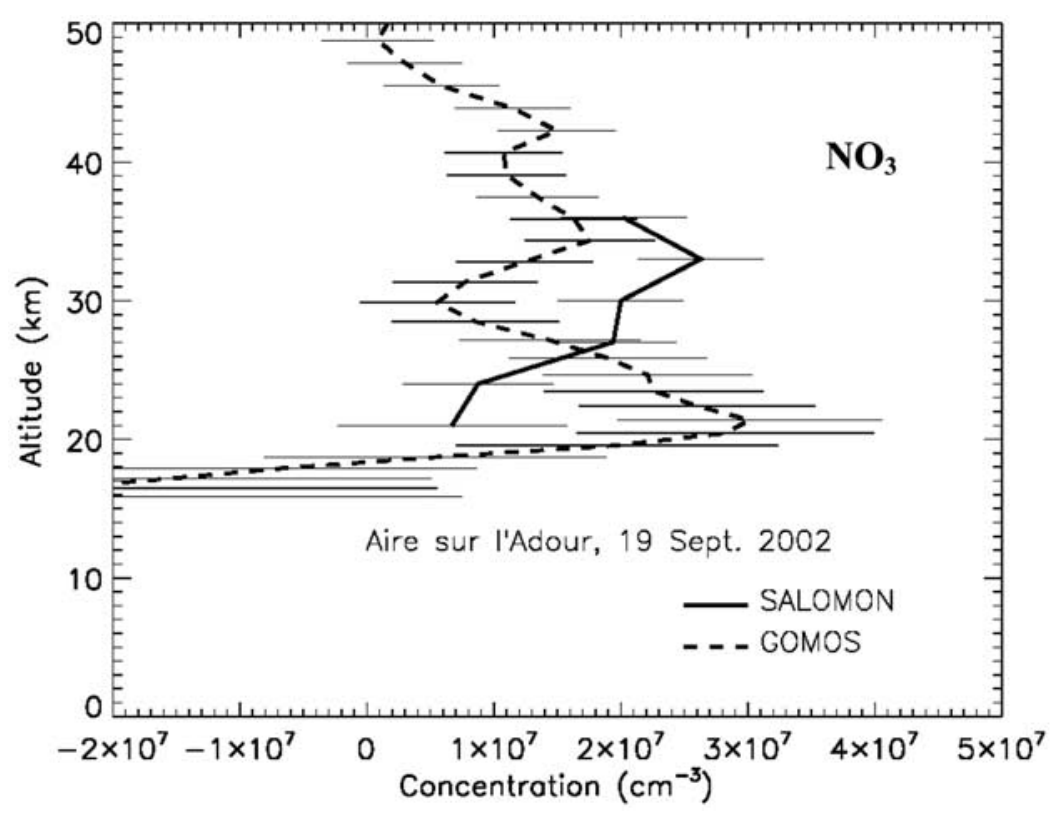

Figure 20. Comparison between $\mathrm{NO}_{3}$ measurements by GOMOS and SALOMON, at midlatitudes.

produced by clouds and aerosols, if incorrectly retrieved for any reason, could affect the ozone retrieval. The second problem is the chromatic scintillation [Renard et al., 2001], which produces low frequency oscillations in the transmission spectra. This phenomenon can induce artificial oscillations in the vertical profiles; then a dedicated smoothing procedure or a regularization must be applied [Kyrölä et al., 1993, 2004; Fussen et al., 2005].

[27] For ozone, the "LPCE processor" uses the spectral window 450 to $680 \mathrm{~nm}$, and a Differential Optical Absorption Spectroscopy (DOAS) method [Platt, 1994], as commonly applied to balloon measurements in this spectral domain. First, the transmission spectra are vertically averaged (sliding smoothing procedure over 3 consecutive spectra), which minimizes efficiently the effect of the chromatic scintillation, as shown by Renard et al. [1996, 2003]. Secondly, the low frequency structures can be removed using the DOAS procedure, minimizing the effect of the residual chromatic scintillation and removing the contribution of aerosols.

[28] The algorithm has been tested for few tens of GOMOS occultations (outside the validation collocations). The algorithm is robust and does not produce unrealistic

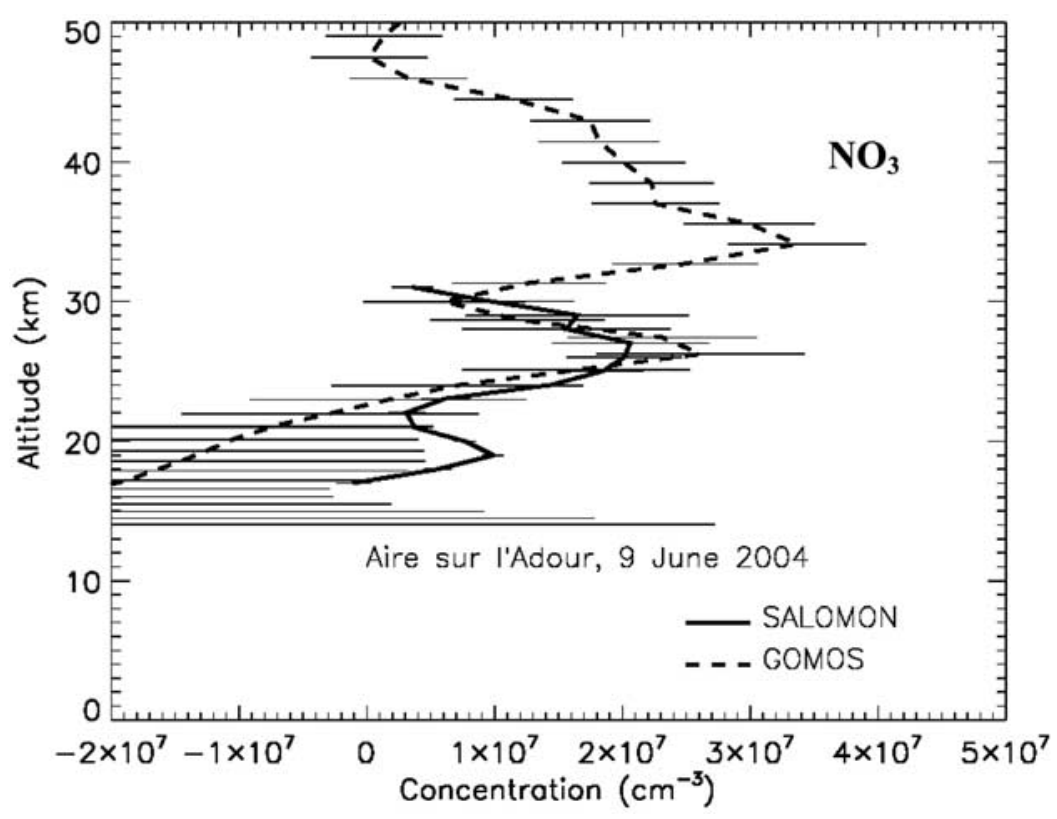

Figure 21. Comparison between $\mathrm{NO}_{3}$ measurements by GOMOS and SALOMON, at midlatitudes. 


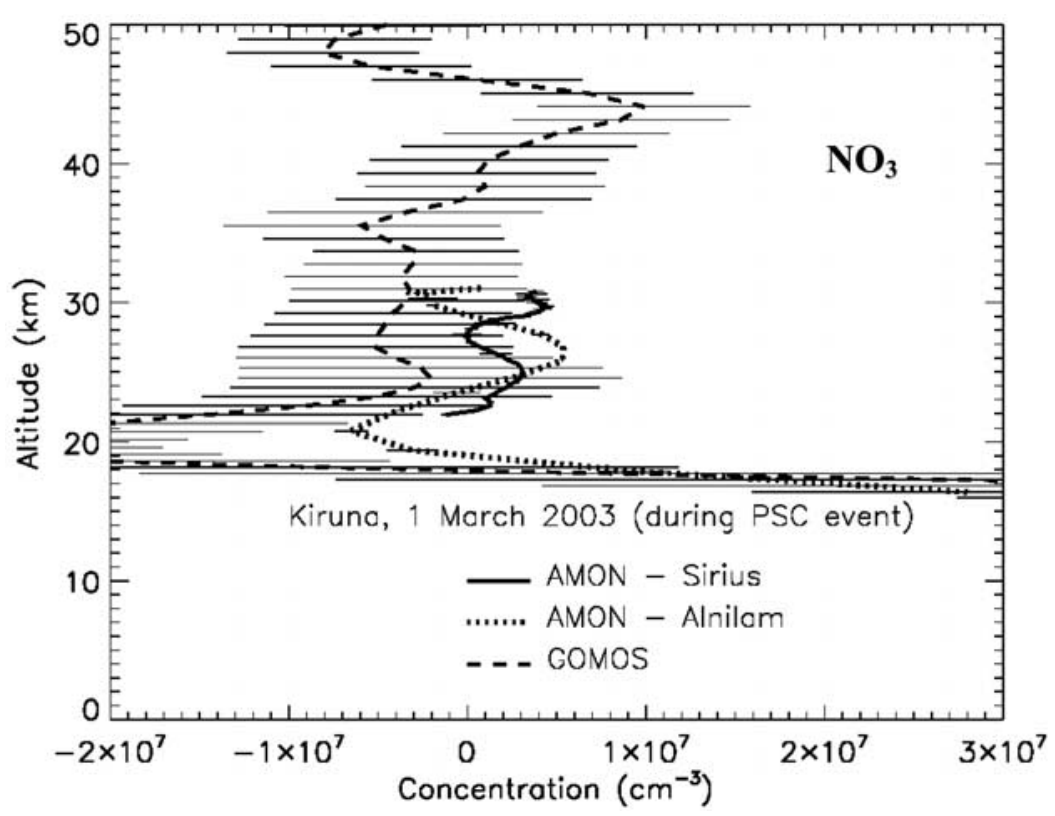

Figure 22. Comparison between $\mathrm{NO}_{3}$ measurements by GOMOS and AMON, at high latitudes.

results. Then it can be used "in routine" for the validation case-studies presented above.

[29] For some cases, the improvements are significant (Figure 24), producing a better agreement between GOMOS and balloon profiles both for the estimation of concentration maximum and of its altitude; for the other cases, only slight changes are obtained. After applying these improvements for all the ozone cases studied above, the difference for the altitude concentration maxima is $0.3 \pm 1.9 \mathrm{~km}$ (instead of $1.5 \pm 2.5 \mathrm{~km}$ ); the difference of the maxima of concentrations is now $-1.2 \times 10^{10} \pm 4.0 \times 10^{11} \mathrm{~cm}^{-3}$ (instead of $9.2 \times 10^{10} \pm 6.1 \times 10^{11}$ molecule $\mathrm{cm}^{-3}$ ), corresponding to a bias of about $0.2 \%$ and slightly reducing the uncertainty to about $7 \%$. Nevertheless, the total uncertainty on the individual profiles is not reduced.

[30] The "operational GOMOS" retrieval uses an "iterative DOAS" method for the $\mathrm{NO}_{2}$ and $\mathrm{NO}_{3}$ retrievals, combining a DOAS technique and the global inversion. For $\mathrm{NO}_{2}$, the "LPCE processor" uses DOAS method restricting the spectral domain to 420 to $550 \mathrm{~nm}$. The peaks of maximum concentrations can be better estimated, both in term of altitude and of absolute values, as seen in Figure 25. Considering all the $\mathrm{NO}_{2}$ profiles presented above, the difference for the altitude of maximum concentration is

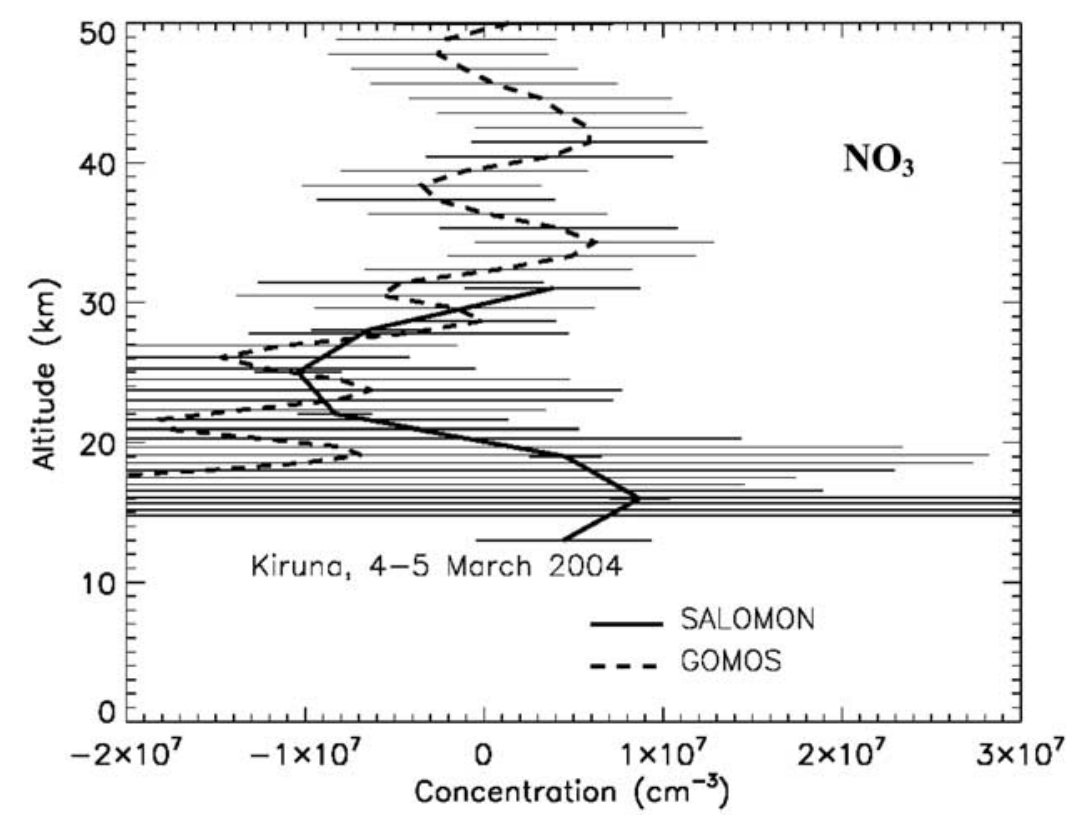

Figure 23. Comparison between $\mathrm{NO}_{3}$ measurements by GOMOS and SALOMON, at high latitudes. 


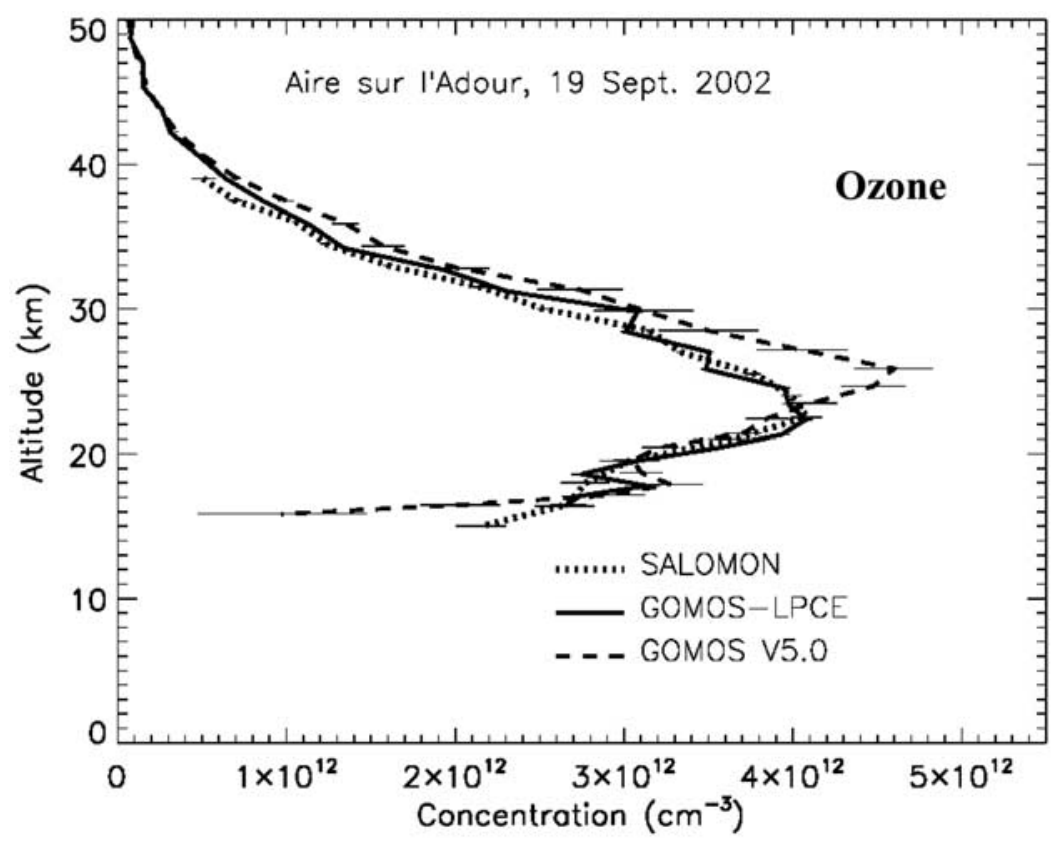

Figure 24. Comparison between ozone measurements by GOMOS and SALOMON, at midlatitudes. GOMOS V5.0 is for current GOMOS products. GOMOS-LPCE is for the profile obtained using the LPCE processor.

$0.2 \pm 1.5 \mathrm{~km}$ (instead of $0.7 \pm 1.3 \mathrm{~km}$ ). Nevertheless, uncertainties for the values of concentration maximum and for the individual profiles are not significantly reduced. Then, this procedure could sometimes help in better estimating the altitude(s) of the peak(s), in particular when secondary enhancements are present (as in Figure 25) but could not help decreasing the uncertainty.
[31] Similar conclusions are obtained for $\mathrm{NO}_{3}$. The retrieval is conducted using the spectral domain restricted from 655 to $670 \mathrm{~nm}$ and centered on the strongest absorption line. Improvements in the shape of the vertical profile can be obtained sometimes, as shown in Figure 26, without reducing the uncertainty.

[32] In conclusion, similar statistical results are obtained using the "operational GOMOS" processor and the "LPCE

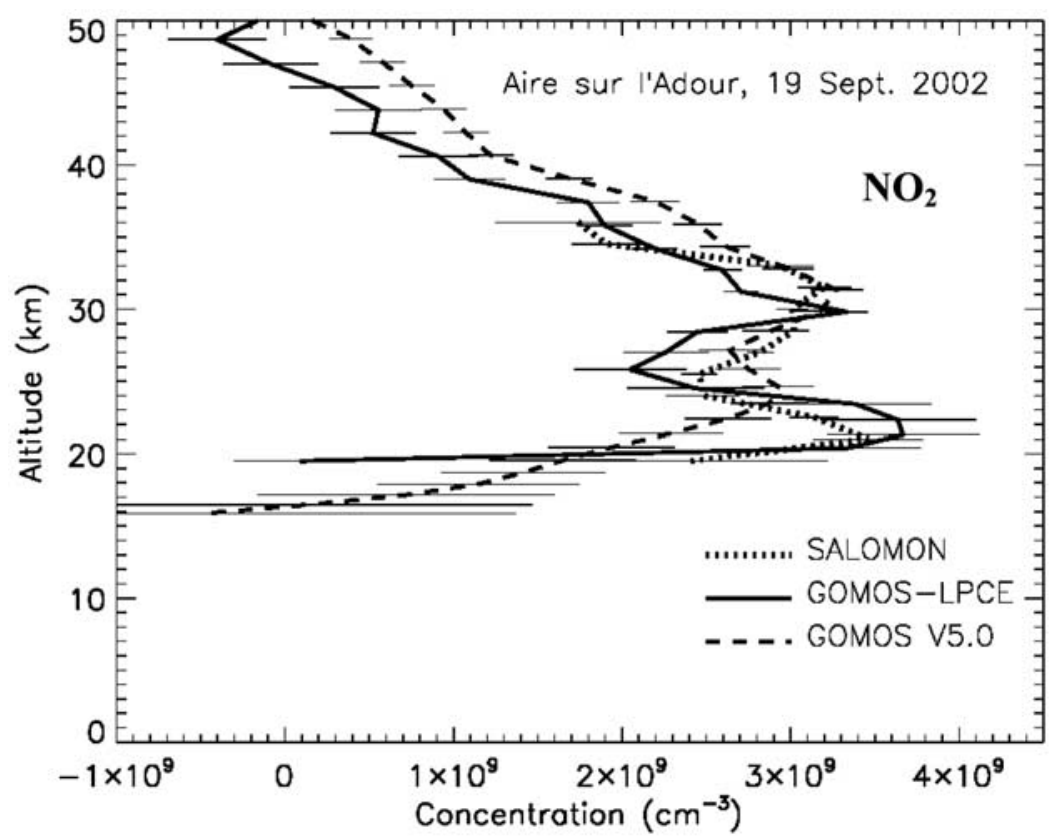

Figure 25. As Figure 24, but for $\mathrm{NO}_{2}$. 


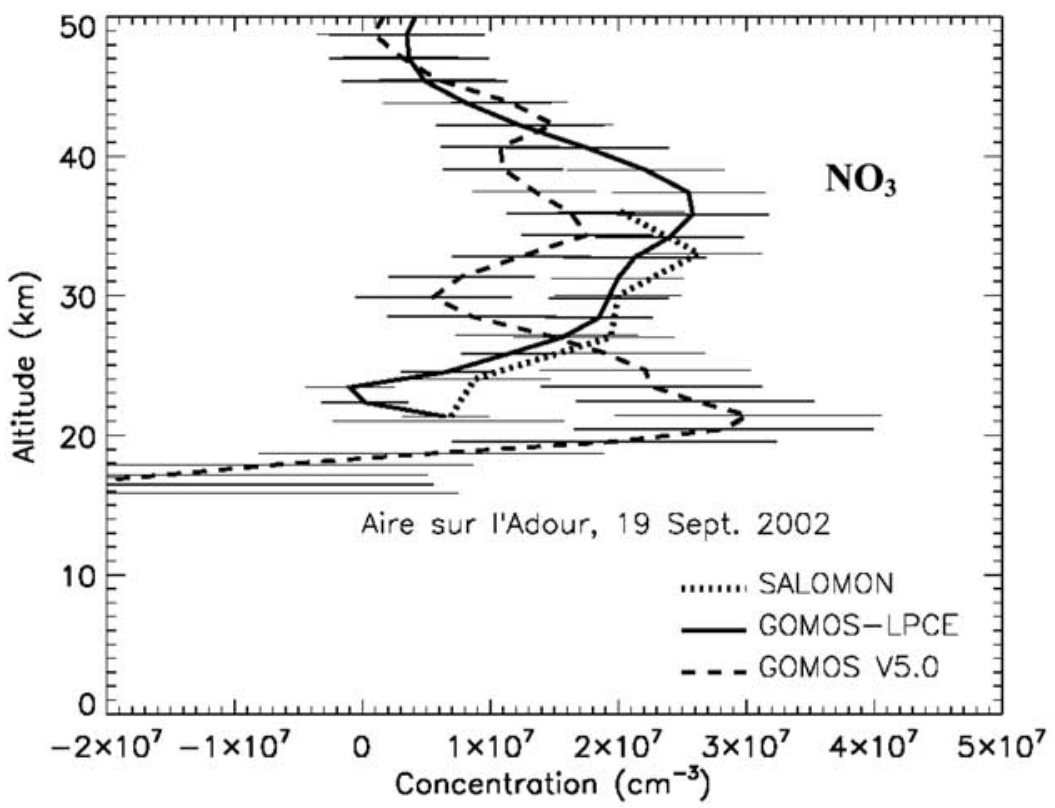

Figure 26. As Figure 24, but for $\mathrm{NO}_{3}$.

processor" when ozone and $\mathrm{NO}_{2}$ GOMOS profiles are compared to balloon profiles. This study confirms that the "operational GOMOS" processor works well.

\section{Comparison Results for Aerosol Extinction}

[33] In general, the validation of aerosol satellite measurements consists of making comparisons of total aerosol content and surface area densities, assuming a priori size distributions and a known refractive index [Russell et al., 1996; Randall et al., 2000; Deshler et al., 2003]. Nevertheless, previous works [Berthet et al., 2002; Renard et al., 2005b] have shown that the wavelength dependence of extinction in the UV-visible domain could exhibit spectral color effects that cannot be reproduced using such assumptions due to the presence of a mixture of solid particles and liquid droplets. Also, the surface area density could be a poor indicator of the absolute content of aerosols and does

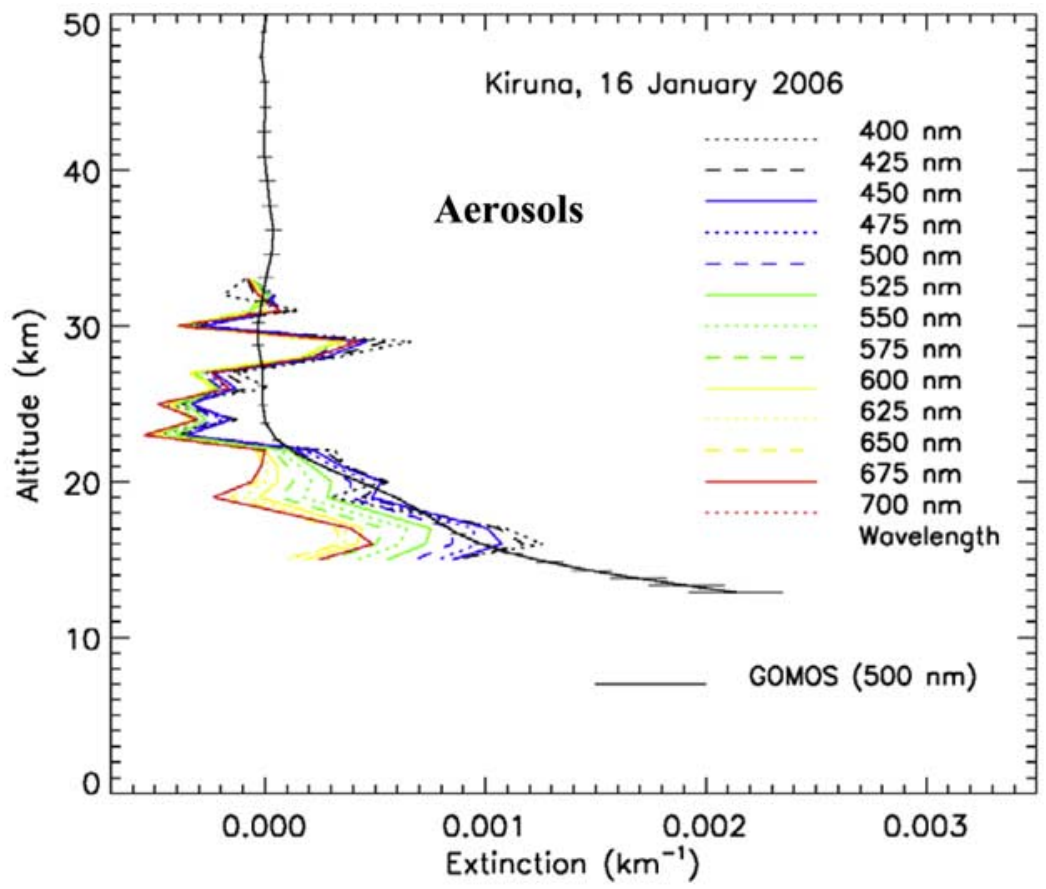

Figure 27. Wavelength dependence of aerosol extinction measured by SALOMON at high latitudes, compared to GOMOS reference value at $500 \mathrm{~nm}$. The error is of $1 \times 10^{-4} \mathrm{~km}^{-1}$. 


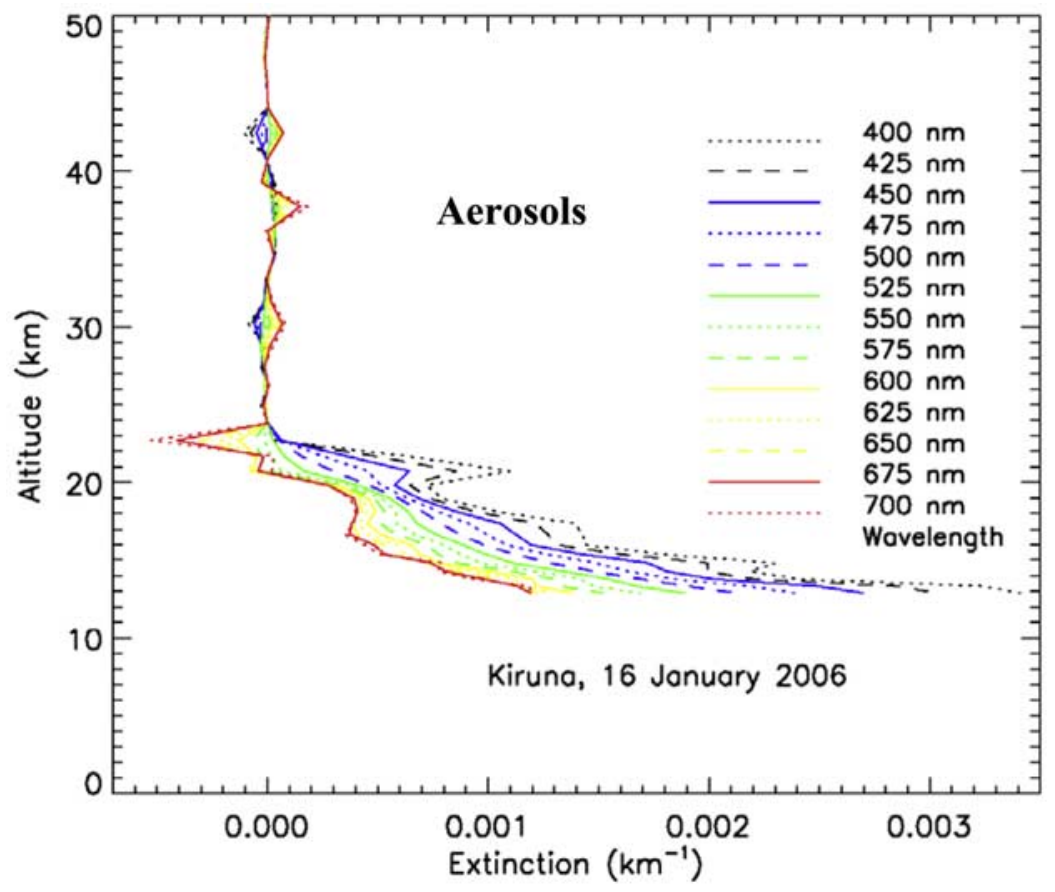

Figure 28. Wavelength dependence of aerosol extinction measured by GOMOS at high latitudes, using the brightest star (Sirius, magnitude -1.4 ).

not allow us to distinguish between the various families of particles [Renard et al., 2002]. Hence we propose here a different approach for validation, by making a direct comparison of the wavelength dependence of the spectral extinction.

[34] The aerosol extinction is given at $500 \mathrm{~nm}$ in the GOMOS V5.0 files. The values at this wavelength can be used in particular for establishing a global climatology of aerosol content [Vanhellemont et al., 2005]. The wavelength dependence of extinction, also available in the files, is given in respect to these "reference" values at $500 \mathrm{~nm}$, in the form of a second order polynomial. The "global inversion" method used for the retrieval could be very sensitive to

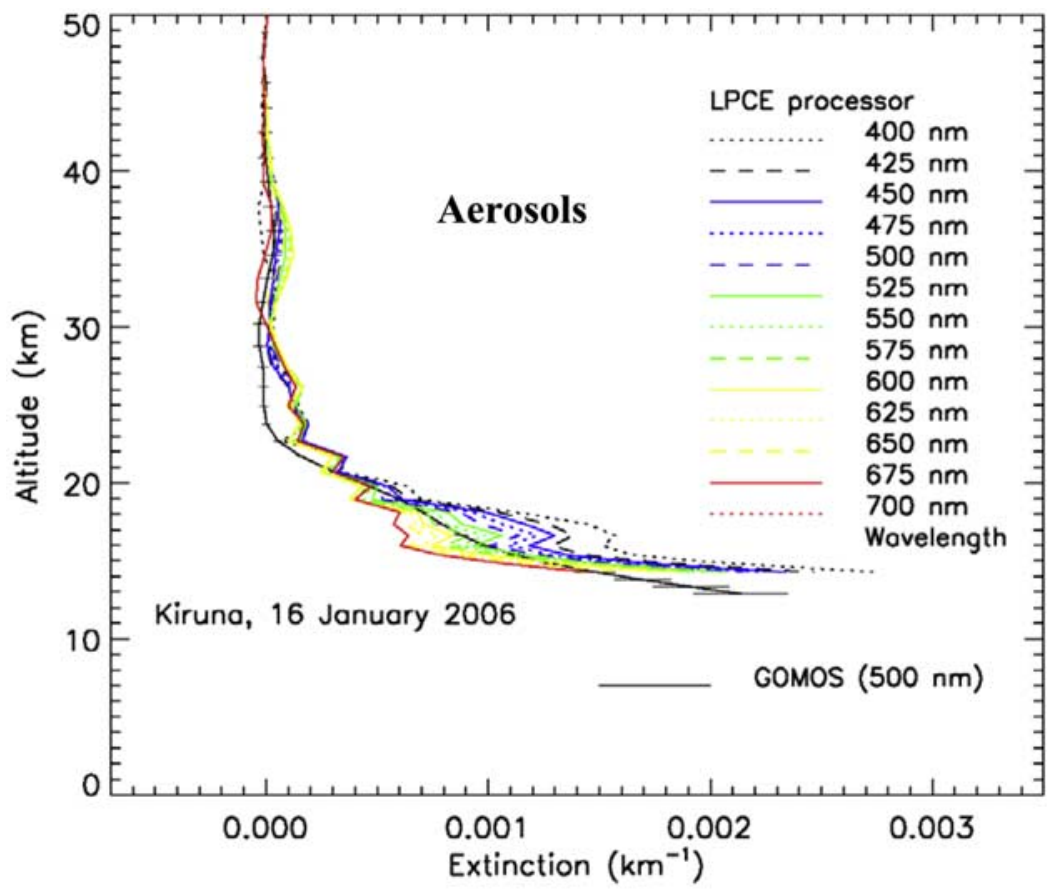

Figure 29. Wavelength dependence of aerosol extinction measured by GOMOS using the LPCE processor, compared to GOMOS reference value at $500 \mathrm{~nm}$. 


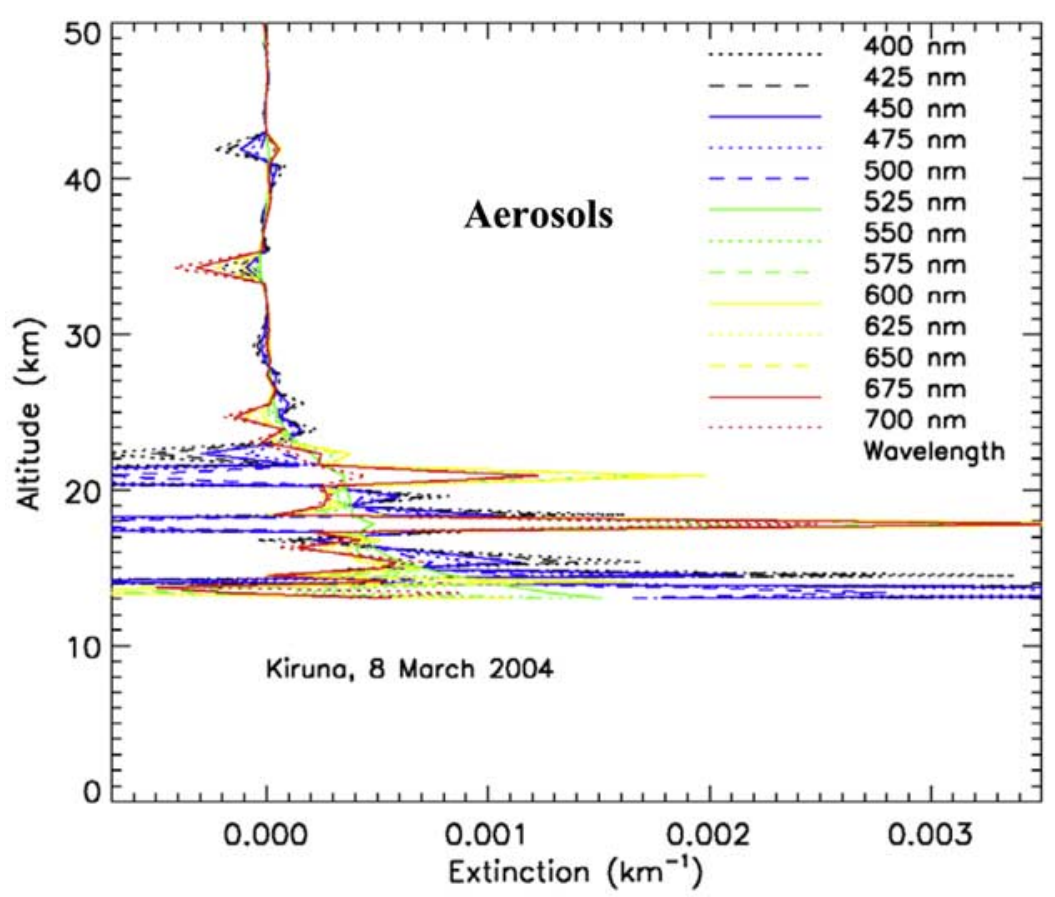

Figure 30. Wavelength dependence of aerosol extinction measured by GOMOS at high latitudes, using a weak star (magnitude 2.7).

noise and to the chromatic scintillation, which can produce artifacts.

[35] There was only one SALOMON flight, on 16 January 2006 from Kiruna (Figure 27), during which GOMOS made its observations on the brightest available star, which is Sirius. The measurements with SALOMON were conducted during the ascent of the balloon, with a positive
Moon elevation (i.e., Moon above the gondola horizon), producing lines of sight with shorter path lengths than for measurements performed at float altitude during the setting or the rising of the Moon. The wavelength dependence of aerosol extinction was determined from 400 to $700 \mathrm{~nm}$ using a fourth order polynomial, allowing us to capture the non-monotonic wavelength dependence of the extinction

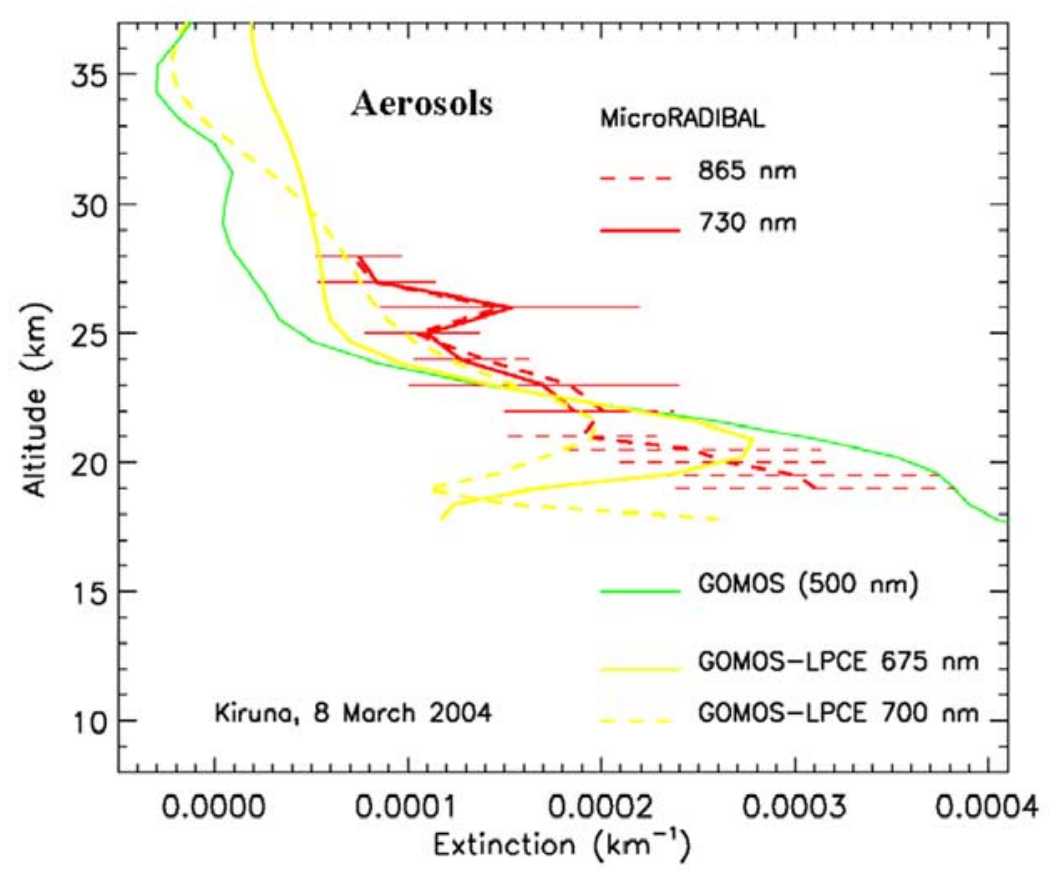

Figure 31. Reference aerosol extinction measured by GOMOS at $500 \mathrm{~nm}$, compared to MicroRADIBAL extinction, and to GOMOS extinction in the red domain using the "LPCE processor". 
produced by the solid particles [Renard et al., 2005b]. The error, coming from 1- $\sigma$ RMS calculation, is of $1 \times 10^{-4}$ $\mathrm{km}^{-1}$ at all altitudes and wavelengths. It can be noticed that SALOMON extinction profiles, exhibit fluctuations of aerosol content in the middle stratosphere. The presence of such local enhancements, confirmed by an aerosol counter onboard the gondola (Renard, J.-B., et al., Vertical distribution of the different types of aerosols in the stratosphere - 1. Detection of liquid particles, interplanetary material and soot, and analysis of their spatial variability using the baloon-borne instruments STAC, SALOMON and Micro-RADIBAL, and the satellite instrument GOMOSEnvisat, submitted to Journal of Geophysical Research, 2007), produce some artificial negative values during the retrieval as shown in Figure 27.

[36] The GOMOS wavelength dependence is presented in Figure 28. The vertical profiles are smoother than for SALOMON; the path length of the GOMOS line of sight is at least ten times longer than for SALOMON, thus diluting the contribution of the local enhancements. The GOMOS and SALOMON profiles are in fair agreement both for estimating the aerosol extinction and its wavelength dependence, in particular below $23 \mathrm{~km}$ with extinction lower in the red domain than in the blue.

[37] As with the other species, we can tentatively apply the "LPCE processor" to the GOMOS data, restricting the spectral domain to 400 to $700 \mathrm{~nm}$ (Figure 29). Excluding the UV domain is motivated by the fact that the signal-tonoise ratio is low in this domain due to the weak flux of the star and the strong effect of Rayleigh scattering. With this method, the local enhancements of aerosol content as well as the presence of particles above $23 \mathrm{~km}$ are better retrieved.

[38] Another validation exercise has been conducted when GOMOS was using a weak star as a light source, on 8 March 2004 above Kiruna. This time, as expected, the wavelength dependence (Figure 30) exhibits strong oscillations that are unrealistic. As above, the "LPCE processor" has been applied to the transmissions in order to test its ability to retrieve the wavelength dependence of aerosols in such conditions. Figure 31 presents the comparison between GOMOS reference data at $500 \mathrm{~nm}$ with the MicroRADIBAL extinction in the near infra red and the GOMOS extinctions in the red domain obtained with the "LPCE processor". The $500 \mathrm{~nm}$ GOMOS data appear to be too high in the lower stratosphere and to be too low in the middle stratosphere, although the vertical columns are in good agreement. Significant improvement can be obtained using the LPCE processor. In this case, the extinction profiles in the red domain (at 675 and $700 \mathrm{~nm}$ ) are close to MicroRADIBAL results, and the presence of aerosols in the middle stratosphere is better estimated. Nevertheless, the "LPCE-processor" retrieval is inaccurate below $20 \mathrm{~km}$ where the profiles at 675 and $700 \mathrm{~nm}$ are vertically uncorrelated.

\section{Conclusion}

[39] The "one shot" validation exercise of GOMOS measurements conducted with different balloon-borne instruments has allowed us to estimate the accuracy of GOMOS measurements in different geophysical conditions. The balloon and GOMOS ozone and $\mathrm{NO}_{2}$ vertical columns are in excellent agreement in the middle stratosphere. The accuracy of individual ozone profiles in the middle stratosphere is about $10 \%$ for ozone; the accuracy is about $25 \%$ for $\mathrm{NO}_{2}$ profiles although the estimation for the concentration maximum is $17 \%$. As for most of satellite measurements, the retrievals are difficult in the lower stratosphere and the individual profiles must be used cautiously. On the other hand, the $\mathrm{NO}_{3}$ retrieval is difficult even in the middle stratosphere and only studies with averaged data can be conducted. At least for the two GOMOS measurements considered here, the aerosol content is well estimated but the estimation of the wavelength dependence must be analyzed only when the brightest stars are observed by GOMOS. Some improvements can be made for better estimating the wavelength dependence of aerosol extinction, performing the retrievals in a spectral window restricted to the visible domain.

[40] It can be concluded that GOMOS has fully respected its primary objective for the study of the trends of species in the middle stratosphere, for which the profiles are used in a statistical manner. On the other hand, some individual profiles could be partly inaccurate, in particular in the lower stratosphere. Improvements could be obtained by reprocessing some transmissions in case of specific studies in the middle and lower stratosphere.

[41] Acknowledgments. The campaigns were funded by the European Space Agency (ESA), the French Space Agency (CNES) and the German Space Agency (DLR). The authors want to thank the CNES launching team and the Swedish Space Corporation team at Esrange for the success of the validation campaigns. The authors thank also Francis Dalaudier and Alain Hauchecorne (Service d'Aéronomie du CNRS) for their useful comments during the preparation of the paper.

[42] Zuyin Pu thanks Yasjka Meijer and another reviewer for their assistance in evaluating this paper.

\section{References}

Alfred, J., M. Fromm, R. Bevilacqua, G. Nedoluha, A. Strawa, L. Poole, and J. Wickert (2006), Observation and analysis of polar stratospheric clouds detected by POAM III and SAGE III during the SOLVE II/VINTERSOL campaign in the 2002/2003 Northern hemisphere winter, Atmos. Chem. Phys. Discuss., 6, 11,391-11,426.

Bertaux, J.-L., et al. (2004), First results on GOMOS/ENVISAT, Adv. Space Res., 33(7), 1029-1035.

Berthet, G., J.-B. Renard, C. Brogniez, C. Robert, M. Chartier, and M. Pirre (2002), Optical and physical properties of stratospheric aerosols from balloon measurements in the visible and near-infrared domains. I. Analysis of aerosol extinction spectra from the AMON and SALOMON balloon-borne spectrometers, Appl. Opt., 41(36), $7522-7539$.

Berthet, G., J.-B. Renard, V. Catoire, M. Chartier, C. Robert, N. Huret, F. Coquelet, Q. Bourgeois, E. D. Rivière, B. Barret, F. Lefèvre, and A. Hauchecorne (2007), Remote sensing measurements in the polar vortex: Comparison to in situ observations and implications for the simultaneous retrievals and analysis of the $\mathrm{NO}_{2}$ and $\mathrm{OClO}$ species, J. Geophys. Res., 112, D21310, doi:10.1029/2007JD008699.

Brogniez, C., N. Huret, S. Eckermann, E. D. Rivière, M. Pirre, M. Herman, J.-Y. Balois, C. Verwaerde, N. Larsen, and B. Knudsen (2003), PSC microphysical properties measured by microRadibal instrument on January 25, 2000 above Esrange and modeling interpretation, J. Geophys. Res., 108(D6), 8332, doi:10.1029/2001JD001017.

Deshler, T., M. E. Hervig, D. J. Hofmann, J. M. Rosen, and J. B. Lile (2003), Thirty years of in situ stratospheric aerosol size distribution measurements from Laramie, Wyoming $\left(41^{\circ} \mathrm{N}\right)$ using balloon-borne instruments, J. Geophys. Res., 108(D5), 4167, doi:10.1029/2002JD002514.

Friedl-Vallon, F., G. Maucher, M. Seefeldner, O. Trieschmann, A. Kleinert, A. Lengel, C. Keim, H. Oelhaf, and H. Fischer (2004), Design and characterization of the balloon-borne Michelson Interferometer for Passive Atmospheric Sounding (MIPAS-B2), Appl. Opt., 43(16), 33353355.

Fussen, D. F., et al. (2005), Autoregressive smoothing of GOMOS transmittances, Adv. Space Res., 36, 899-905. 
Fussen, D., et al. (2006), A global OClO stratospheric layer discovered in GOMOS stellar occultation measurements, Geophys. Res. Lett., 33, L13815, doi:10.1029/2006GL026406.

Hauchecorne, A., et al. (2005), First simultaneous global climatology of night-time stratospheric $\mathrm{NO}_{2}$ and $\mathrm{NO}_{3}$ observed by GOMOS/ENVISAT in 2003, J. Geophys. Res., 110, D18301, doi:10.1029/2004JD005711.

Kyrölä, E., E. Sihvola, Y. Kotivuori, M. Tikka, and T. Tuomi (1993), Inverse theory for occultation measurements, 1. Spectral inversion, J. Geophys. Res., 98, 7367-7381.

Kyrölä, E., et al. (2004), GOMOS on Envisat: an overview, Adv. Space Res., 33, 1020-1028.

Marchand, M., S. Bekki, A. Hauchecorne, and J.-L. Bertaux (2004), Validation of the self-consistency of GOMOS $\mathrm{NO}_{3}, \mathrm{NO}_{2}$ and $\mathrm{O}_{3}$ data using chemical data assimilation, Geophys. Res. Lett., 31, L10107, doi:10.1029/ 2004GL019631.

Meijer, Y. J., et al. (2004), Pole-to-pole validation of Envisat GOMOS ozone profiles using data from ground-based and balloon sonde measurements, J. Geophys. Res., 109, D23305, doi:10.1029/2004JD004834.

Moreau, G., C. Robert, V. Catoire, M. Chartier, C. Camy-Peyret, N. Huret, M. Pirre, L. Pomathiod, and G. Chalumeau (2005), A multi-species in situ balloon-borne instrument with six diode laser spectrometers, $\mathrm{Appl}$. Opt., 44(28), 5972-5989.

Platt, U. (1994), Differential optical absorption spectroscopy (DOAS), Chem. Anal. Series, 127, 27-83.

Pommereau, J.-P., and J. Piquard (1994), Ozone, nitrogen dioxide and aerosol vertical distribution by UV-visible solar occultation from balloon, Geophys. Res. Lett., 21, 1227-1230.

Randall, C. E., R. M. Bevilacqua, J. D. Lumpe, K. W. Hoppel, D. W. Rusch, and E. P. Shettle (2000), Comparison of Polar Ozone and Aeroso Measurements (POAM) II and Stratospheric Aerosol and Gas Experiment (SAGE II) aerosols measurements from 1994 to 1996, J. Geophys. Res. 105, 3929-3942.

Randall, C. E., et al. (2005), Stratospheric effects of energetic particle precipitation in 2003-2004, Geophys. Res. Lett., 32, L05802, doi:10.1029/2004GL022003.

Renard, J.-B., M. Pirre, C. Robert, D. Huguenin, G. Moreau, and J. M. Russell (1996), Nocturnal distribution of stratospheric $\mathrm{O}_{3}, \mathrm{NO}_{2} \& \mathrm{NO}_{3}$ from balloon measurements, J. Geophys. Res., 101, 28,793-28,804.

Renard, J.-B., M. Chartier, C. Robert, G. Chaluneau, G. Berthet, M. Pirre, J.-P. Pommereau, and F. Goutail (2000), SALOMON: A new light balloon-borne UV visible spectrometer for night-time observations of stratospheric trace gas species, Appl. Opt., 39(3), 386-392.

Renard, J.-B., F. Dalaudier, A. Hauchecorne, C. Robert, T. Lemaire, M. Pirre, and J.-L. Bertaux (2001), Measurements of stratospheric chromatic scintillation by balloon-borne spectrometer AMON-RA, Appl. Opt., 40(24), 4254-4260.

Renard, J.-B., G. Berthet, C. Robert, M. Chartier, M. Pirre, C. Brogniez, M. Herman, C. Verwaerde, J.-Y. Balois, J. Ovarlez, H. Ovarlez, J. Crespin, and T. Deshler (2002), Optical and physical properties of stratospheric aerosols from balloon measurements in the visible and near-infrared domains. II. Comparison of extinction, reflectance, polarization and counting measurements, Appl. Opt., 41(36), 7540-7549.

Renard, J.-B., M. Chartier, G. Berthet, C. Robert, T. Lemaire, F. Pepe, M. George, and M. Pirre (2003), Validation of GOMOS vertical profiles using the stratospheric balloon-borne AMON and SALOMON UV- visible spectrometers, Proceeding of the 16th ESA Symposium on European Rocket and Balloon Programmes and Related Research, Eur. Space Agency, Spec. Publ.-530, 415-420.

Renard, J.-B., M. Chipperfield, G. Berthet, F. Goffinont-Taupin, C. Robert, M. Chartier, H. Roscoe, W. Feng, and M. Pirre (2005a), Analysis of $\mathrm{NO}_{3}$ vertical profile measurements from remote sensing balloon-borne spectrometers and comparison with model calculations, J. Atmos. Chem., 51, $65-78$.

Renard, J.-B., J. Ovarlez, G. Berthet, D. Fussen, F. Vanhellemont, C. Brogniez, E. Hadamcik, M. Chartier, and H. Ovarlez (2005b), Optical and physical properties of stratospheric aerosols from balloon measurements in the visible and near-infrared domains. III. Presence of aerosols in the middle stratosphere, Appl. Opt., 44(19), 4086-4095.

Renard, J.-B., P.-L. Blelly, Q. Bourgeois, M. Chartier, F. Goutail, and Y. Orsolini (2006), Origin of the January-April 2004 increase in stratospheric $\mathrm{NO}_{2}$ observed in the northern polar latitudes, Geophys. Res. Lett., 33, L11801, doi:10.1029/2005GL025450.

Rivière, E. D., et al. (2000), Role of lee waves in the formation of solid polar stratospheric clouds: Case studies from February 1997, J. Geophys. Res., 105(D5), 6845-6853

Russell, P. B., et al. (1996), Global to microscale evolution of the Pinatubo volcanic aerosol derived from diverse measurements and analyses, J. Geophys. Res., 101, 18,747-18,763.

Seppälä, A., P. T. Verronen, E. Kyrölä, S. Hassinen, L. Backman, A. Hauchecorne, J.-L. Bertaux, and D. Fussen (2004), Solar proton events of October-November 2003: Ozone depletion in the Northern Hemisphere polar winter as seen by GOMOS/Envisat, Geophys. Res. Lett., 31, L19107, doi:10.1029/2004GL021042.

Vanhellemont, F., et al. (2005), A 2003 stratospheric aerosol extinction and PSC climatology from GOMOS measurements on Envisat, Atmos. Chem. Phys., 5, 2413-2417.

Wetzel, G., H. Oelhaf, F. Friedl-Vallon, A. Kleinert, A. Lengel, G. Maucher, H. Nordmeyer, R. Ruhnke, H. Nakajima, Y. Sasano, T. Sugita, and T. Yokota (2006), Intercomparison and validation of ILAS-II version 1.4 target parameters with MIPAS-B measurements, J. Geophys. Res., 111 D11S06, doi:10.1029/2005JD006287.

F. Auriol, J.-Y. Balois, C. Brogniez, P. François, and C. Verwaerde, LOA/ CNRS, Villeneuve d'Ascq, Université des sciences et technologie de Lille, F-59655, Villeneuve d'Ascq cedex, France.

G. Berthet, V. Catoire, M. Chartier, B. Gaubicher, J.-B. Renard, and C. Robert, LPCE-CNRS/Université d'Orléans, 3A av. de la recherche scientifique, F-45071, Orléans cedex 2, France. (jbrenard@cnrs-orleans.fr)

D. Fussen, IASB, 3 avenue circulaire, B-1180, Brussels, Belgium.

F. Goutail and J.-P. Pommereau, Service d'Aéronomie, BP 3, F-91370, Verrières le Buisson cedex, France.

H. Oelhaf and G. Wetzel, Institut für Meteorologie und Klimaforschung, Forschungszentrum Karlsruhe GmbH, P.O. Box 3640, 76021, Karlsruhe, Germany.

H. K. Roscoe, British Antarctic Survey/NERC, Madingley Road, Cambridge, CB3 0ET, UK

P. Wursteisen, European Space Agency, ESTEC-SMS, Postbus 299, NL2200, AG Noordwijk, Netherlands. 